\title{
Phonemic similarity effects and prelexical phonology
}

\author{
GEORGIJE LUKATELA \\ University of Belgrade, Belgrade, Yugoslavia \\ and \\ M. T. TURVEY \\ University of Connecticut, Storrs, Connecticut \\ and Haskins Laboratories, New Haven, Connecticut
}

\begin{abstract}
Ten experiments were conducted on visually presented Serbo-Croatian words and pseudowords, comprising phonemically similar and dissimilar context-target sequences. There were five main results. First, phonemic similarity effects in both lexical decision and naming are independent of graphemic similarity. Second, phonemic similarity need not facilitate lexical decision; the direction of its effect depends on lexicality, target frequency, and type of similarity (specifically, the position of the phoneme that distinguishes context and target). Third, phonemic similarity expedites the naming of words and pseudowords, and to the same degree. Fourth, phonemic similarity is negated in naming, but not in lexical decision, when the visually presented context and target are stressed differently. Fifth, the phonemic similarity effect occurs even when the context is a masked pseudoword. These results are discussed in terms of a model in which wordprocessing units are activated routinely by phoneme-processing units, and in which compositionally similar word units, when activated, inhibit one another in proportion to each's familiarity. In this model, the phonemic similarity effect in naming is based on the states of phoneme units, whereas the phonemic similarity effect in lexical decision is based on the states of word units. Overall, the results comport with an account in which phonology is computed prelexically and automatically.
\end{abstract}

\section{Codes for Visual Lexical Access}

Enduring questions in the study of word perception concern phonological information and its role. Is phonological information made available routinely in visual lexical access? Is phonological information generated prelexically or postlexically? If phonological information mediates visual access to a word's representation, is the mediation obligatory or optional? There is evidence to suggest that visual word recognition may be mediated by phonological recoding (e.g., Meyer, Schvaneveldt, \& Ruddy, 1974). At the same time, strong arguments can be found for the contrary view, namely that visual word recognition can proceed independently of phonological recoding (e.g., Forster \& Chambers, 1973). These contrasting observations have led to the development of dual-route models. Roughly, the idea is that the skilled reader of English has an option of using either the visual or phonological route (McCusker, Hillinger, \& Bias, 1981). There is a marked tendency, however, to deemphasize the

This research was supported in part by National Institute of Child Health and Human Development Grants HD-08495 and HD-01994 to the University of Belgrade and Haskins Laboratories, respectively. The second author held a James McKeen Cattell Fellowship during the preparation of this manuscript. Requests for reprints may be sent to M. T. Turvey, Haskins Laboratories, 270 Crown Street, New Haven, CT 06511.

-Accepted by previous editor, Alice F. Healy phonological contribution to word recognition. The deemphasis takes two forms. One promotes visual access as the faster of the two routes and, therefore, the route on which successful reading depends most commonly. The other underscores that most, if not all, of the evidence for phonological processes comes from negative decision data, suggesting that the main contribution of phonological processes is to the perception of letter strings that are pseudowords (Coltheart, Davelaar, Jonasson, \& Besner, 1977).

In the dual-route model, the visual and phonological routes operate in parallel, with the phonological code derived on the basis of grapheme-to-phoneme correspondences (GPCs). The idea is that GPCs operate by breaking down a word into its constituent graphemes and assigning each one its appropriate phonemic code. It has been argued that if prelexical phonological recodings are produced by using GPC rules, then such recodings can only occur for words that conform to these rules, that is, so-called "regular words"' (Coltheart, Besner, Jonasson, \& Davelaar, 1979). The lexical entries of words that are exceptions to the rules can be accessed only via the visual route. Consequently, whether or not the lexical decision task involves the use of GPCs might be evaluated by determining whether performance is better with regular words than with exception words. Unfortunately, regularity effects in English word processing prove to be elusive when measured in lexical decision, with the result 
that the evaluation of the GPC process in terms of regularity effects has been inconclusive (see Humphreys \& Evett, 1985). More convincing evidence for GPCs is to be found in studies with Serbo-Croatian.

\section{Visual Word Recognition in Serbo-Croatian}

The script system of Serbo-Croatian contrasts in two important ways with that of English. First, it occurs in two forms: Roman and Cyrillic alphabets. These two alphabets share a number of letters (in uppercase: A, E, $\mathrm{O}, \mathrm{J}, \mathrm{K}, \mathrm{M}, \mathrm{T}, \mathrm{H}, \mathrm{P}, \mathrm{C}, \mathrm{B})$, some of which $(\mathrm{H}, \mathrm{P}, \mathrm{C}$, B) designate one phoneme in one alphabet and another phoneme in the other alphabet (e.g., Lukatela \& Turvey, 1980). Second, individual letters within an alphabet map uniquely to individual phonemes, and individual phonemes map uniquely to individual letters; the orthography is shallow (see Frost, Bentin, \& Katz, 1987; Lukatela, Popadić, Ognjenović, \& Turvey, 1980; Lukatela \& Turvey, 1980). Previous research has suggested that a prelexically derived phonology plays a major role in word recognition and word naming in Serbo-Croatian (e.g., Feldman \& Turvey, 1983; Frost et al., 1987; Lukatela et al., 1980). The empirical support has come primarily from the phonological ambiguity effect.

There are written words in Serbo-Croatian that comprise only shared letters. Some of these contain phonemically ambiguous letters. Consider the letter string BETAP. Read strictly through the letter-to-sound correspondences of the Cyrillic alphabet, this letter string is pronounced / vetar/ and is a high-frequency noun meaning "wind." Read strictly through the letter-to-sound correspondences of the Roman alphabet, BETAP is pronounced /betap/, a pseudoword. Read with a mixture of the two sets of correspondences, Cyrillic and Roman, it is pronounced /vetap/ and /betar/, which are also pseudowords. The word meaning "wind" is transcribed in the Roman alphabet as VETAR. This letter string supports only a single reading, /vetar/. No other readings are possible. VETAR, unlike its Cyrillic mate, BETAP, is phonologically unambiguous.

In the lexical decision, the acceptance latencies for BETAP, and for words like it, are considerably longer than the acceptance latencies for VETAR, and for words like it, even though BETAP and VETAR are equal in frequency, syllabic structure, number of letters, and meaning. This contrast defines what is referred to as the phonological ambiguity effect (PAE). It is argued that accepting BETAP as a word is made more difficult by the fact that it activates more phoneme units and, therefore, activates partially more competing word units than does VETAR (Lukatela, Turvey, Feldman, Carello, \& Katz, 1989). Importantly, PAE satisfies Coltheart et al.'s (1977) and Van Orden's (1987) criterial requirement for the demonstration of phonological mediation in lexical access: Phonological effects are demonstrated in positive lexical decisions. The effect of phonological ambiguity on "yes" responses means that phonology cannot be considered as a representation that is delayed relative to visual lexical access. Let us turn to the major supplementary features of PAE. In our view, they provide a stubborn set of facts favoring the automatic involvement of prelexical phonology in lexical access.

1. PAE occurs for pseudowords. Rejection latencies are slowed for the phonologically ambiguous pseudoword BEMAP relative to its phonologically unambiguous pseudoword mate, VEMAR. Arguably, BEMAP is coded into more phonological forms than is VEMAR, and BEMAP's rejection latencies are, therefore, slowed relative to those for VEMAR. If pseudowords do not have lexical entries, as is commonly argued, then their phonological representations must be derived prelexically through letter-phoneme correspondences, or " postlexically" by analogy (Glushko, 1979; Kay \& Marcell, 1981). Because PAE occurs for both words and pseudowords, and because PAE is due to phonological factors, it seems likely that phonological information is activated automatically given a letter string.

2. PAE is generally larger for words than for pseudowords. With one exception (Lukatela, Carello, Savić, \& Turvey, 1986, using lateralized displays), PAE has proven to be more pronounced in word than pseudoword lexical decision times. On the basis of English-language research, the argument has been made that phonological coding must be optional and rare in ordinary word recognition because phonological factors influence pseudoword processing more so than word processing (Coltheart et al., 1977; Henderson, 1982; McCusker et al., 1981). Applying this logic to the Serbo-Croatian results, phonological coding must be mandatory and routine in ordinary word recognition because phonological factors influence word processing more so than pseudoword processing (e.g., Feldman \& Turvey, 1983; Lukatela, Feldman, Turvey, Carello, \& Katz, 1989; Lukatela et al., 1980).

3. PAE occurs in both lexical decision and naming. As noted, lexical decision and naming appear to be sensitive differentially to prelexical and postlexical influences. It is argued that effects obtained with lexical decision but not naming are postlexical effects and that those obtained with both tasks are prelexical (Balota \& Chumbley, 1985; Seidenberg, Waters, Sanders, \& Langer, 1984; West \& Stanovich, 1982). PAE is found repeatedly in both lexical decision and naming tasks (e.g., Lukatela, Feldman, et al., 1989; Lukatela, Turvey, et al., 1989). According to the preceding criteria, PAE is prelexical.

4. PAE can be reduced by an immediately preceding context that specifies the alphabet of BETAP-type words. The difference between lexical decision latencies to BETAP and VETAR is minimized or eliminated when BETAP is preceded by a Cyrillic letter string (that is, a context written with unique Cyrillic letters specifying, thereby, the same alphabet as that in which BETAP is a word) and VETAR is preceded by a Roman letter string (Lukatela, Turvey, et al., 1989). Importantly, PAE is reduced equivalently by a nonword, consonant string context with no orthographic resemblance to BETAP that specifies the alphabet in which BETAP is a word, and 
a word context that does the same thing (Lukatela, Turvey, et al., 1989). Apparently, some process at the level of letter units can reduce the number of phonemic representations of BETAP from four to one, thereby rendering it similar to VETAR. The implication is that the origin of PAE is prelexical.

5. PAE is not eliminated by experimental conditions that encourage suppressing phonological coding. In one experiment, subjects were encouraged to process all items as written in Roman (Lukatela, Savić, Gligorijević, Ognjenović, \& Turvey, 1978, Experiment 1). Unique Cyrillic letters never appeared. The phonologically ambiguous words were words in Roman and nonwords in Cyrillic; they comprised only $9 \%$ of the total stimuli. Another 9\% of the stimuli were phonologically ambiguous pseudowords, making only a total of $18 \%$ that could be read alternatively as Cyrillic. In sum, the experiment of Lukatela et al. (1978) encouraged using only the Roman letterphoneme correspondences or using a visual word-specific code. PAE was, however, pronounced. In another experiment (Feldman \& Turvey, 1983), the phonologically ambiguous letter strings that were words were words in their Cyrillic reading and all the subjects were people who had learned Cyrillic as their first alphabet. The optimal strategy would have been to suppress the (Roman) nonword reading in favor solely of the (Cyrillic) word reading or simply to use a visual word-specific code. Again, PAE was pronounced. In English-language experiments that involve phonologically ambiguous stimuli (homophones, pseudohomophones), high percentages are recommended to avoid biasing the subject to a phonological coding strategy (Davelaar, Coltheart, Besner, \& Jonasson, 1978; Hawkins, Reicher, Rogers, \& Peterson, 1976). The idea is that when the experiment conditions are unfavorable to the use of phonological coding (it results in slowed and inaccurate responses), then phonological coding is abandoned in favor of strictly visual access. Serbo-Croatian experiments have been conducted in which $50 \%$ of all stimuli were phonologically ambiguous, half of the time in Cyrillic and half of the time in Roman (Lukatela, Feldman, et al., 1989). If visual access had been used, the slowing-down and errors induced by the phonological code would have been avoided. Once again, PAE was in evidence. Clearly, PAE is indifferent to wide variations in experimental conditions (e.g., 12.5\% ambiguous stimuli in Feldman, Kostić, Lukatela, \& Turvey, 1983, to $50 \%$ ambiguous stimuli in Lukatela, Feldman, et al., 1989). The implication is that PAE is due to an automatic process, not an optional or strategic process, and that the automatic process involves phonology.

6. PAE is not the consequence of phonologically ambiguous words' being associated with intrinsically slower responses due to lexical entries with higher activation thresholds. It has been hypothesized that visual access usually provides enough information for lexical decisions to be made, but sometimes the accessing is sufficiently slow (e.g., the word is infrequent, the spelling is irregular, the subject is tardy) to allow lexically derived pho- nology a role in the decision process (Seidenberg, 1985). To reiterate, the difference between lexical decision latencies to BETAP and VETAR is minimized or eliminated when BETAP is preceded by a Cyrillic letter string (that is, a context in the same alphabet as that in which BETAP is a word) and VETAR is preceded by a Roman letter string (Lukatela, Turvey, et al., 1989). The implication is that there is nothing especially different about the lexical entries of BETAP and VETAR, their spellings, or the kinds of information they make available postlexically. PAE seems to depend on prelexical rather than postlexical processes.

7. PAE is independent of familiarity/frequency. The inflected nouns of Serbo-Croatian are most frequent and most prominent grammatically in the nominative singular form. A common finding is that nominative singulars are responded to faster than are oblique forms (e.g., Lukatela, Carello, \& Turvey, 1987). For example, VENA ("vein" in nominative singular) is responded to much faster than is VENI (same word in dative or locative singular). However, if VENA and VENI are written in Cyrillic (that is, BEHA and BEHИ, respectively), the less frequent and less grammatically prominent dative/locative form (BEHИ) is responded to faster. The latency difference between BEHA and VENA is large and defines PAE; the latencies to BEHИ and VENA do not differ (Feldman et al., 1983). Furthermore, if latency to the unambiguous form of a word is taken as a measure of experiential familiarity with the word, PAE in lexical decision does not vary in magnitude with experiential familiarity (Feldman \& Turvey, 1983). The implication is that PAE is not governed by biases (e.g., activation thresholds, grammatical significance) at the level of lexical entries.

8. PAE depends on the number of ambiguous letters. Effects dependent on the number of letters or syllables in a word have been used as indices of phonological recoding (Forster \& Chambers, 1973; Frederiksen \& Kroll, 1976; Green \& Shallice, 1976). Letter length effects occur regularly in naming but rarely, if ever, in lexical decision (Henderson, 1982). The lack of such effects in lexical decision is used to argue that phonological coding cannot take place. KOTBA has one ambiguous letter (B), BETAP has two ambiguous letters ( $B$ and $P$ ), and CABAHA has three ( $C, B$, and $H)$. In each example, the remaining unambiguous letters are shared letters. In the lexical decision task, with such stimuli, PAE is larger, the greater the number of ambiguous letters (Feldman et al., 1983; Feldman \& Turvey, 1983). Conversely, other research shows that the effect in lexical decision is smaller, the greater the number of unique letters (Lukatela, Feldman, et al., 1989). The implication is that PAE is based on an analytic process that heeds the phonological aspects of the printed word as specified in the details of its orthographic structure (Turvey, Feldman, \& Lukatela, 1984).

9. PAE can appear as false negative responses. Rejection of a BETAP-type word as a word occurred in the Serbo-Croatian experiments on a high proportion of the 
times (in the range of $19 \%$ to $26 \%$ ) such a word was presented; however, in those experiments, average false negatives on phonologically unambiguous words were in the range of $1 \%$ to $4 \%$. High average of the false negatives responses on phonologically ambiguous words suggests a mental process in which the representation activating the lexicon does not correspond to a word. This is understandable if PAE is due to the facts that (1) BETAP can give rise to a number of phonological representations that do not correspond to a word and (2) the lexicon is accessed through phonological representations.

10. PAE can appear as false positive responses. There are two significant types of phonologically ambiguous pseudowords. One type, like BEMAP, comprises letter strings that are (1) composed of shared letters, one or more of which are ambiguous, (2) unreadable as a word in either Roman or Cyrillic, and (3) unreadable as a word in a mixture of both alphabets. The other type satisfies (1) and (2) but not (3). An example of the second type is the pseudoword HAPEB. If the letter-phoneme correspondences of both alphabets are applied to HAPEB, one of the resulting eight phonological descriptions corresponds to a word (namely, /napev/, meaning "tune"). It comes about by assigning the phoneme $/ \mathrm{n} /$ to $\mathrm{H}$ by the Cyrillic alphabet, the phoneme /p/to P by the Roman alphabet, and the phoneme / $/ \mathrm{t}$ to $\mathrm{B}$ by the Cyrillic alphabet. Compare HAPEB to a pseudoword of the first type, such as BEMAP. BEMAP has all but one letter in common with a real world (BETAP), and all but one phoneme in common with this real word. HAPEB similarly has all but one letter in common with a real word (HAПEB). However, HAPEB has all phonemes in common with a real word, if both alphabets apply.

If lexical access is visual, false positives to BEMAP and HAPEB should be few and equal. In contrast, if lexical access is based on phonemic descriptions computed prelexically, and if the computation is analytic, assigning as many phonemes per letter as permitted, then false positives should be greater for HAPEB. Experimentation shows that BEMAP and its unambiguous pseudoword control, VEMAR, generate the same small number of false positives (about $2 \%-3 \%$ ). When preceded by a neutral context word, HAPEB generated $31 \%$ false positives; when preceded by an associate of /napev/ (namely, MELODIJA, meaning "melody"), HAPEB generated $55 \%$ false positives (Lukatela, Feldman, et al., 1989; Lukatela, Turvey, et al., 1989). These results are understandable if PAE with pseudowords is due to the facts that (1) a phonologically ambiguous pseudoword can give rise automatically to all of the phonological representations that its letter structure permits, (2) for some phonologically ambiguous pseudowords, one of the automatically generated phonological representations corresponds to a word, and (3) the lexicon is accessed through phonological representations.

Let us put the preceding survey of PAE features in perspective. Various experimental criteria have been advanced by investigators of English word processing for deciding whether or not phonological coding mediates the accessing of word information. The criteria were incorporated in the preceding survey. These experimental criteria have not been satisfied in English-language studies, with the one recent and important exception of Van Orden's research (Van Orden, 1987; Van Orden, Johnston, \& Hale, 1988). In contrast, most of the criteria have been satisfied in Serbo-Croatian language studies.

\section{Facilitating Word Recognition by Phonemic Similarity}

One strategy for addressing questions of prelexical phonology is to examine how the visual processing of a given word (the target word) is influenced by the degree of shared phonemic and graphemic similarity between it and a preceding word (the context word). In the original application of this strategy, using lexical decision latency as the measure of word processing, it was observed that TRIBE following BRIBE was responded to faster than TRIBE following FENCE, and that BREAK following FREAK was responded to more slowly than was BREAK following COUCH (Meyer et al., 1974). Meyer et al. interpreted these results to mean that phonological information is automatically accessed in visual word recognition and, specifically, that people tend to use the same letter-phoneme conversion rules on the target as are used on the context. Meyer et al. argued for an encoding bias hypothesis: If a phoneme code mediates lexical access, lexical decision should be more rapid when the letter-tophoneme mappings are similar for context and target (BRIBE-TRIBE) and more slow when the letter-tophoneme mappings are dissimilar for context and target (FREAK-BREAK).

Subsequent research has raised doubts about the encoding bias hypothesis. First, it appears that the TRIBEBRIBE effect and the BREAK-FREAK effect result from different mechanisms. When the stimuli requiring a "no" response are orthographically illegal strings rather than pseudowords (orthographically legal, pronounceable nonwords), the inhibition of BREAK by FREAK disappears (Hanson \& Fowler, 1987; Shulman, Hornak, \& Sanders, 1978). The BREAK-FREAK effect also disappeared when a delay of the order of $250 \mathrm{msec}$ intervened between context and target (Hillinger, 1980). In contrast, the phonemic similarity effect-the facilitation of TRIBE by BRIBE - persisted over these manipulations of context type and time. Second, the phonemic similarity effect endured when the context was presented auditorily, and it was of the same magnitude whether the context was graphemically dissimilar (EIGHT-MATE) or graphemically similar (LATE-MATE) (Hillinger, 1980).

Recently, Martin and Jensen (1988) conducted a series of five visual lexical decision experiments in which they used word targets preceded by graphemically similar or graphemically dissimilar primes that rhymed with the target. In none of these experiments was the phonemic similarity effect observed. The failure to replicate the most important of Hillinger's (1980) results led Martin and 
Jensen (1988) to suggest that either (1) the internal lexicon is not organized such that spreading activation occurs on the basis of phonemic similarity or (2) visual lexical decisions are made without phonological mediation. Other kinds of experiments have questioned the automatic activation of phonological information on which the encoding bias hypothesis is based. The observation of longer latencies in the regular lexical decision task to homophonic words, such as YOKE (Rubenstein, Lewis, \& Rubenstein, 1971), fails to hold when such words occur rarely in the experiment (Davelaar et al., 1978). More robust is the pseudoword homophonic effect in which TRATE-type items yield slower rejection latencies. It has been argued, however, that because the latter is a phonological effect in slower (nonword) responses, it is unlikely to occur in faster (word) responses. That is, word processing may occur ordinarily without a prelexical phonological code (Coltheart et al., 1979; Henderson, 1982; McCusker et al., 1981). New results, however, are more favorable to the view that phonology mediates lexical access in English word recognition (Perfetti, Bell, \& Delaney, 1988; Van Orden, 1987; Van Orden et al., 1988).

\section{Investigating the Phonemic Similarity Effect in Serbo-Croatian}

In the present article, we investigate the phonemic similarity effect and pursue the main points of Meyer et al.'s (1974) original thesis, which states that a prelexical phonology is involved in fluent word processing and that it can be biased by the phonological features of preceding contexts. The present article is distinguished from previous research on the phonemic similarity effect by its use of both lexical decision and naming tasks and by its use of Serbo-Croatian-a language, as noted above, that differs from English in terms of the relative complexity of computing phonology from script.

The influence of contextual information on visual wordprocessing tasks has been found to depend not only on the kind of context but also on the nature of the task. The lexical decision and naming tasks have emerged as necessary converging operations to be considered in any evaluation of context effects, because they appear to be differentially sensitive to prelexical and postlexical influences (Carello, Lukatela, \& Turvey, 1988; Forster, 1979; Seidenberg et al., 1984; Stanovich \& West, 1983; West \& Stanovich, 1982, 1986). The argument is that effects obtained with both tasks are prelexical in origin and those obtained only in lexical decision are postlexical in origin, wherein "prelexical" refers to processes of activating word information and "postlexical" refers to processes that use this information (Balota \& Chumbley, 1985; Seidenberg et al., 1984; West \& Stanovich, 1982). The fundamental difference between the two tasks can be expressed in signal-detection terminology (Seidenberg et al., 1984): Lexical decision involves sensitivity and bias; naming involves only sensitivity. The point is that, in naming, there is no criterion to be referred to because there is no decision to be made.
With respect to the relevance of the phonemic similarity effect to issues of phonological coding, the most significant finding would be that it was independent of graphemic similarity: EIGHT primes MATE. This result of Hillinger (1980), though seriously questioned by Martin and Jensen (1988), would suggest that the phonemic similarity effect results strictly from the use in target processing of phonological information activated by the context. Hillinger's (1980) demonstration that EIGHT primed MATE, compared EIGHT-MATE (phonemically similar, graphemically dissimilar) with the pairs LATEMATE (phonemically similar, graphemically similar) and VEIL-MATE (phonemically dissimilar, graphemically dissimilar). With respect to lexical decision times, the two rhyming pairs did not differ from each other, and both differed from the control. A later test of independence from graphemic similarity was conducted by Evett and Humphreys (1981) using a masking procedure and percent correct identification. They compared the difference between FILE-TILE and its control with the difference between $\mathrm{COUCH}-\mathrm{TOUCH}$ and its control and found them to be the same, concluding thereby that the increased recognition of TILE following FILE could be accounted for strictly in terms of graphemic factors. In other masking experiments (Humphreys, Evett, \& Taylor, 1982), and in lexical decision experiments (Hanson \& Fowler, 1987), it has been the case, however, that orthographically similar rhyming pairs show greater facilitation than do orthographically dissimilar nonrhyming pairs.

Where different word pairs are contrasted, the outcome can be contaminated by frequency, semantic, and other uncontrolled differences. Automatic postlexical checks for associativeness, syntactic agreement, and semantic coherence could differ between pairs like FILE-TILE and COUCH-TOUCH. In the Hillinger (1980) study, EIGHTMATE and LATE-MATE are different word pairs and are, therefore, obviously different in other ways than graphemically dissimilar versus graphemically similar. Consider as further examples of Hillinger's stimuli, HEARD-BIRD and THIRD-BIRD, FRUIT-ROOT and LOOT-ROOT, WEIRD-BEARD and GEAREDBEARD, SEWS-HOSE and ROSE-HOSE. These contrasts on the dimension of graphemic similarity include also contrasts in syntactic coherence, associativeness, frequencies of the context items (e.g., LOOT $=3 /$ million, FRUIT $=35 /$ million; Kučera \& Francis, 1967), and the word types that are paired (e.g., verb-noun vs. numbernoun, adjective-noun vs. verb-noun, and so on). A distinct advantage of Serbo-Croatian is that it provides a way of evaluating the independence of the phonemic similarity effect from graphemic similarity with the same word pairs. This is achieved by writing the context word and the target word in the same alphabet, for example, PUTIĆ ("lane" written in Roman)-PUŽIĆ ("snail" written in Roman), or in different alphabets, ЛУТИЋ ("lane" written in Cyrillic)-PUŽIĆ. In sum, Serbo-Croatian permits a pure test of the independence of the phonemic similarity effect from graphemic similarity. If the phonemic 
similarity effect passes the test, then the claim that phonological information underwrites this phenomenon of visual word processing would be secure. The focus of inquiry can then turn to the issue of where and when in word processing such information is made available.

\section{EXPERIMENT 1}

Experiment 1 was an attempt to replicate for SerboCroatian Hillinger's (1980) observation that the successive visual presentation of two phonemically similar words affects the lexical decision to the second word and does so independently of graphemic similarity. On each trial, lexical decision was made on a target preceded by a context that was phonemically similar (differing from the target only in the middle consonant) or dissimilar. Also manipulated was the graphemic similarity between context and target. This was done by presenting the context in either the same alphabet as the target or in the other alphabet. Importantly, this way of manipulating graphemic similarity preserves the same phonological relation over graphemically similar sequences, for example, PUTIĆPUŽIĆ (Type lb, see Table 1) and graphemically dissimilar sequences, for example, ЛУТИЋ-PUŽIĆ (Тype 2b), where PUTIĆ and ЛУТИ' $h$ are the same context word written in Roman and Cyrillic, respectively. To show the phonemic similarity effect under conditions of graphemic dissimilarity is to provide evidence that phonological information is automatically accessed; target lexical decision is affected by the context word's phonology rather than by the context word's orthography or form. In Experiment 1 , the phonemic similarity effect was tested by exploiting four stimulus types (illustrated in Table 1). Contexts and targets were: (1) phonemically and graphemically similar, written in the same alphabet; (2) phonemically similar and graphemically dissimilar, written in different alphabets (half of targets were Roman and half were Cyrillic); (3) phonemically and graphemically dissimilar, written in the same alphabet; and (4) phonemically and graphemically dissimilar, written in different alphabets (half Roman and half Cyrillic). Phonemically dissimilar pairs (Types 3 and 4) provide a baseline for the corresponding phonemically similar pairs (Types 1 and 2 , respectively).

Four other features require highlighting. First, Englishlanguage experiments have used word sets dominated by monosyllabic words; in Experiment 1, two- and threesyllable words were used primarily because of the rarity of monosyllabic words in Serbo-Croatian. Second, in English experiments, phonemic similarity between pseudowords cannot always be defined unequivocally, because the pronunciation of pseudowords may be ambiguous. Experiment 1 used word-pseudoword pairs for which the phonemic similarity relation is unambiguous. This feature follows from the facts that the Serbo-Croatian writing system (both Roman and Cyrillic) is phonemically precise and that all letters in a word are pronounced. Thus, a word context that differs from a pseudoword target in

Table 1a

Examples of Phonemically Similar Words in the Same Alphabet (Type 1 Pairs) that Share All Letters/Phonemes

Except for the Initial (a), Middle (b), or Final Letter/Phoneme (c)

Type of Pair

la

lb

$1 \mathrm{c}$

(n)

\begin{tabular}{|c|c|}
\hline \multicolumn{2}{|c|}{ Examples } \\
\hline $\begin{array}{l}\text { KUVAR-CUVAR } \\
\text { (cook-guardian) }\end{array}$ & $\begin{array}{l}\text { ЖИВАЦ-ЛИВАЦ } \\
\text { (nerve-smelter) }\end{array}$ \\
\hline $\begin{array}{l}\text { PUTIĆ-PUŽIĆ } \\
\text { (lane-snail) }\end{array}$ & $\begin{array}{l}\text { РАКУН-РАЧУН } \\
\text { (racoon-bill) }\end{array}$ \\
\hline $\begin{array}{l}\text { GUSAR-GUSAN } \\
\text { (pirate-gander) }\end{array}$ & $\begin{array}{l}\text { Путић-Пужић } \\
\text { (lane-snail) }\end{array}$ \\
\hline
\end{tabular}

Table 1b

Examples of Phonemically Similar Words in Different Alphabets (Type 2 Pairs) that Differ Either in the Initial (a), Middle (b), or Final Phoneme (c), and that Share No More Than One Letter

\begin{tabular}{|c|c|c|}
\hline Type of Pair & & \\
\hline $2 a$ & $\begin{array}{l}\text { KYBAP-CUVAR } \\
\text { (cook-guardian) }\end{array}$ & $\begin{array}{l}\text { ŽIVAC-ЛИВАЦ } \\
\text { (nerve-smelter) }\end{array}$ \\
\hline $2 b$ & $\begin{array}{l}\text { ПУТИЋ-PUŽIĆ } \\
\text { (lane-snail) }\end{array}$ & $\begin{array}{l}\text { RAKUN-PAЧYH } \\
\text { (racoon-bill) }\end{array}$ \\
\hline $2 c$ & $\begin{array}{l}\text { ГУCAP-GUSAN } \\
\text { (pirate-gander) }\end{array}$ & $\begin{array}{l}\text { PASUS-ПАСУЛ } \\
\text { (paragraph-beans) }\end{array}$ \\
\hline
\end{tabular}

Table lc

Examples of Phonemically Dissimilar Words in the Same Alphabet (Type 3 Pairs) and Phonemically Dissimilar Words in Different Alphabets (Type 4) with No More Than One Shared Letter/Phoneme

\begin{tabular}{|c|c|}
\hline Type 3 & Type 4 \\
\hline $\begin{array}{l}\text { PASUS-CUVAR } \\
\text { (paragraph-guardian) }\end{array}$ & $\begin{array}{l}\text { П ACYC-CUVAR } \\
\text { (paragraph-guardian) }\end{array}$ \\
\hline $\begin{array}{l}\text { РАКУН-ЛИВАЦ } \\
\text { (racoon-smelter) }\end{array}$ & $\begin{array}{l}\text { RAKUN-ЛИВАЦ } \\
\text { (racoon-smelter) }\end{array}$ \\
\hline $\begin{array}{l}\text { GUSAR-PUŽIÍ } \\
\text { (pirate-snail) }\end{array}$ & $\begin{array}{l}\text { ГYCAP-PUŽIĆ } \\
\text { (pirate-snail) }\end{array}$ \\
\hline $\begin{array}{l}\text { КУВАР-РАЧУН } \\
\text { (cook-bill) }\end{array}$ & $\begin{array}{l}\text { KUVAR-PAЧУН } \\
\text { (cook-bill) }\end{array}$ \\
\hline $\begin{array}{l}\text { PUTIĆ-GUSAN } \\
\text { (lane-gander) }\end{array}$ & $\begin{array}{l}\text { ПУYTИh-GUSAN } \\
\text { (lane-gander) }\end{array}$ \\
\hline $\begin{array}{l}\text { ЖИВАЦ-ПАСУЉ } \\
\text { (nerve-beans) }\end{array}$ & $\begin{array}{l}\text { ŽIVAC-ПАСУЉ } \\
\text { (nerve-beans) }\end{array}$ \\
\hline
\end{tabular}

one letter is phonemically identical to the target with respect to all letter positions but one. Third, context-target pairs that are graphemically similar but phonemically dissimilar (e.g., FREAK-BREAK) cannot appear in SerboCroatian experiments, because the phonetic precision of the Serbo-Croatian orthography does not permit grapheme-phoneme dissociations of the kind represented by FREAK-BREAK. Fourth, phonemic similarity can be of different types depending on the position of the unshared phoneme or phonemes. In Experiment 1, context and target in a phonemically similar pair differed in the middle consonant. They were phonemically similar but did not rhyme according to the standard definition.

\section{Method}

Subjects. Seventy-six high school seniors from the Fifth Belgrade Gymnasium were paid to serve in Experiment 1. Each subject was assigned to one of four counterbalancing groups according to his or her appearance at the laboratory. 
Table 2

Examples of Context-Target Pairs Used in Experiments 1 and 5 in which Members Differ in a Letter/Phoneme Near the Middle

\begin{tabular}{|c|c|c|c|c|c|}
\hline \multicolumn{2}{|c|}{ Target } & \multicolumn{4}{|c|}{ Context Word } \\
\hline Word & Pseudoword & Type $1 b^{*}$ & Type $3 *$ & Type $2 b^{*}$ & Type 4 \\
\hline $\begin{array}{l}\text { PUŽIĆC } \\
\text { RACUN }\end{array}$ & $\begin{array}{l}\text { PUDIĆ } \\
\text { RAŽUN }\end{array}$ & $\begin{array}{l}\text { PUTIĆ } \\
\text { RAKUN }\end{array}$ & $\begin{array}{l}\text { RAKUN } \\
\text { PUTIĆ }\end{array}$ & $\begin{array}{l}\text { ПУТИћ } \\
\text { РАКУН }\end{array}$ & $\begin{array}{l}\text { РАКУН } \\
\text { ПУТИҺ }\end{array}$ \\
\hline $\begin{array}{l}\text { ЛИКЕР } \\
\text { БУХАЧ }\end{array}$ & $\begin{array}{l}\text { ЛИГЕР } \\
\text { БУЉАЧ }\end{array}$ & $\begin{array}{l}\text { ЛИДЕР } \\
\text { БУКАЧ }\end{array}$ & $\begin{array}{l}\text { БУКАЧ } \\
\text { ЛИДЕР }\end{array}$ & $\begin{array}{l}\text { LIDER } \\
\text { BUKAČ }\end{array}$ & $\begin{array}{l}\text { BUKAĆ } \\
\text { LIDER }\end{array}$ \\
\hline $\begin{array}{l}\text { BUTINA } \\
\text { RITANJE }\end{array}$ & $\begin{array}{l}\text { BUŠINA } \\
\text { RIFANJE }\end{array}$ & $\begin{array}{l}\text { BULINAA } \\
\text { RIBANJE }\end{array}$ & $\begin{array}{l}\text { RIBANJE } \\
\text { BULINA }\end{array}$ & $\begin{array}{l}\text { БУЉИНА } \\
\text { РИБАњЕ }\end{array}$ & $\begin{array}{l}\text { РИБАњЕ } \\
\text { БУЉИНА }\end{array}$ \\
\hline $\begin{array}{l}\text { СУШЕЊЕ } \\
\text { ЖИЛИЦА }\end{array}$ & $\begin{array}{l}\text { СУЉЕњЕ } \\
\text { ЖИФИЦА }\end{array}$ & $\begin{array}{l}\text { СУБЕҢЕ } \\
\text { ЖИЧИЦА }\end{array}$ & $\begin{array}{l}\text { ЖИЧИЦА } \\
\text { СУБЕњЕ }\end{array}$ & $\begin{array}{l}\text { SUDENJE } \\
\text { ŽIČ́ICA }\end{array}$ & $\begin{array}{l}\text { ŽIČICA } \\
\text { SUDENJE }\end{array}$ \\
\hline
\end{tabular}

* The type of context-target pair (identified in Table 1) that is produced by pairing the given context word with the target.

\begin{abstract}
Materials. Seventy-two word-word pairs were selected that were phonemically and, if written in the same alphabet, graphemically similar. To be considered phonemically similar, they could differ by only one letter. Word pairs were chosen so that this different letter was a consonant in the middle or approximately in the middle. Contexts and targets were chosen to be as similar as possible with respect to accent position (i.e., syllable) and type (i.e., short rising, short falling, long rising, or long falling) and without any associative or semantic relationship. All words were nouns (masculine and feminine), all in the nominative singular grammatical form. They comprised two or three syllables and four, five, or six letters, with the majority being two-syllable, five-letter words. Seventy-two pseudoword targets were derived from the word targets by changing the one consonant that was different from the context (so that pseudowords could also be considered to be derived
\end{abstract} from the contexts).

Examples of context-target pairs in Experiment 1 are given in Table 2. Context words are associated with the type numbers that are explained in Table 1. Each type occurred with both word and pseudoword targets.

Design. A given context was seen by an individual subject twice, once preceding the word target and once preceding the derived pseudoword target. When the word was Roman, the corresponding pseudoword was Cyrillic and vice versa. A given subject never encountered a target word or target pseudoword in any of the pairs more than once, but every subject saw every type of pair (1, 2, 3 , and 4), and every target appeared in every type of pair. These constraints were met with four counterbalancing groups. In total, each subject saw 144 experimental stimulus pairs ordered randomly. The experimental sequence was preceded by 32 practice pairs of the same type (although the pairs were less successful in satisfying the constraints on stimulus selection).

Procedure. A subject was seated before the CRT of an Apple Ile computer in a dimly lit room. A fixation point was centered on the screen. On each trial, the subject heard a brief warning signal after which a word appeared above the fixation point for $500 \mathrm{msec}$. After a 100 -msec interstimulus interval, another letter string appeared below the fixation point for $500 \mathrm{msec}$. The subjects were instructed to decide as rapidly as possible whether or not the second string was a word. To ensure that subjects were reading the contexts, they were asked occasionally by a computer message to report orally both stimuli after the lexical decision had been made (on average, approximately every 15 trials). Decisions were indicated by depressing with both thumbs a telegraph key for a "no" response or by depressing another key, slightly further away, with both forefingers for a "yes" response. Latencies were measured from the onset of the target. If the response latency was longer than $1,500 \mathrm{msec}$, a message appeared on the screen requesting that the subject respond more quickly, but long decision times were included in the anal- ysis. The intertrial interval was $2,500 \mathrm{msec}$. The experimental sequence was preceded by a practice sequence of eight different stimulus pairs of the same four types. After one quarter of the trials, there was a brief rest. The next quarter was again preceded by eight practice fillers, as were the third quarter, and the fourth. Within each quarter, context-target types were ordered randomly.

\section{Results and Discussion}

Minimum and maximum acceptable latencies were set at 250 and $2,000 \mathrm{msec}$, respectively. Responses outside of this range were counted as errors. The foregoing conventions applied throughout the series of experiments. Table 3 shows the word and pseudoword mean reaction times, standard deviations, and errors. An analysis of variance was conducted with the factors of phonemic similarity (similar/dissimilar), alphabet (same/other), and lexicality (word/pseudoword). The main effect of phonemic similarity was significant $\left[\min F^{\prime}(1,190)=4.71\right.$, $p<.05$ ], but phonemically similar contexts hindered rather than aided lexical decision (similar $=836 \mathrm{msec}$ vs.

Table 3

Mean Decision Latencies ( $L$; in $\mathrm{msec})$ and

Error Rate (ER; in \%), with the Corresponding Standard Deviation by Subjects and by Items in Experiment 1

\begin{tabular}{lcccc}
\hline & \multicolumn{4}{c}{ Phonemic Relation } \\
\cline { 2 - 4 } Alphabet & \multicolumn{2}{c}{ Similar } & Dissimilar \\
\cline { 2 - 5 } Same & L & ER & Word Target & ER \\
& $807^{*}$ & 5.26 & 792 & 5.48 \\
& $97 \dagger$ & 6.28 & 105 & 6.70 \\
Other & $70 \ddagger$ & 6.96 & 73 & 7.25 \\
& 820 & 5.48 & 793 & 5.12 \\
& 104 & 6.32 & 102 & 6.20 \\
& 64 & 7.25 & 59 & 7.85 \\
Same & & Pseudoword Target & & \\
& 851 & 2.49 & 854 & 3.07 \\
& 111 & 3.56 & 113 & 4.57 \\
Other & 67 & 4.33 & 69 & 5.21 \\
& 865 & 2.85 & 853 & 2.34 \\
& 106 & 3.90 & 100 & 3.30 \\
& 62 & 4.41 & 62 & 3.63 \\
\hline
\end{tabular}

*Mean. †Standard deviation by subjects. $\ddagger$ Standard deviation by items. 
dissimilar $=823 \mathrm{msec}$ ). The analysis also revealed a significant effect of lexicality (words $=803 \mathrm{msec}$ vs. pseudowords $=857 \mathrm{msec})\left[\min F^{\prime}(1,207)=32.44, p<\right.$ $.001]$, but neither the main effect of alphabet (same $=$ $827 \mathrm{msec}$ vs. other $=833 \mathrm{msec})\left[\min F^{\prime}(1,217)=1.48\right.$, $p>.05]$ nor its interaction with phonemic similarity $\left[\min F^{\prime}(1,210)=2.04, p>.05\right]$ were significant. Although lexical decision on words appeared to exhibit a larger negative phonemic similarity effect than did lexical decision on pseudowords, there was no significant similarity by lexicality interaction $\left[\min F^{\prime}(1,210)=1.27\right.$, $p>.05]$. For the analysis of variance conducted on the error data, only lexicality proved significant $\left[\min F^{\prime}(1,205)=15.21, p<.001\right]$.

Obviously, phonemic similarity affected lexical decision on words independently of the alphabetic relation between context and target (e.g., ЛУТИТ-PUŽIĆ compared with PUTIĆ-PUŽIĆ), demonstrating that the effect was governed by phonemic similarity and not by orthographic or form similarity. However, in contrast to the positive effect observed by Hillinger (1980), the phonemic similarity effect of Experiment 1 was negative. A major difference between Experiment 1 and Hillinger's experiments is that his stimuli differed in the initial consonant or consonants (e.g., LOAD-TOAD, THIEF-GRIEF), whereas those of Experiment 1 differed in the middle consonant.

Analysis of the lexical decision task suggests a number of variables likely to affect the magnitude and direction of the phonemic similarity effect. In approximate terms, a word stimulus presented for lexical decision does the following: (1) It activates feature-, letter-, and phonemeprocessing units; it activates, via letter and/or phoneme units, all word units that share components (letters/ phonemes) of its structure, with the degree of activation varying with the degree of overlap; (2) it sets off inhibitory activity among activated, compositionally similar word units, which trims the number of units competing for recognition (McClelland \& Rumelhart, 1981); and (3) it engages a signal-detection capability that evaluates the activity levels of word units against a criterion. When a target word follows a phonemically similar or dissimilar context word, the processes just identified repeat and modulate those that have occurred recently before, as well as being modulated by them.

We elaborate on three points in the preceding. First, the activations of processing units by the different parts of a word stimulus need not be in synchrony (e.g., initial letters may induce these activities sooner than middle and terminal letters). Relatedly, the letters in a word need not be uniformly informative for identification purposes (Merikle \& Glick, 1976) and need not contribute linearly to the phonemic similarity effect (Evett \& Humphreys, 1981). Second, increases and decreases in the activity levels of partially activated word units, and the inhibition levels they incur, need not be constant in magnitude and rate but are likely to be variable, depending on a unit's frequency, number of components, and so on (McClelland
\& Rumelhart, 1981). Third, the evaluation process need not use a constant criterion of acceptance but one that varies with the ratio of the highest activation level to the average activation level and with the discriminability of current and recent stimuli (Balota \& Chumbley, 1985; Norris, 1986). We ought to expect the magnitude and direction of the phonemic similarity effect, therefore, to be complexly determined.

Three readily manipulated variables of likely significance emerge from the foregoing considerations: (1) the type of phonemic similarity, that is, the letter positions in which the context and target overlap phonemically, (2) the frequency of the target word, and (3) the frequency of the context word. In Experiment 2, we make a direct comparison between the two different similarity types, initial different and middle different, in order to evaluate the contribution of the position of the unshared phoneme to the direction of the phonemic similarity effect. In Experiment 3, we repeat the initial different versus middle different position manipulation and add a manipulation of target-word frequency. In Experiment 4, the phonemic similarity type comprising words that differ in final consonants is examined and the frequencies of both context words and target words are manipulated. Each of the experiments employed the lexical decision task.

\section{EXPERIMENT 2}

In Experiment 2, we compare the effects of phonemic similarity for stimuli that differ in either the initial or the middle consonant and that differ graphemically (one word in each context-target pair is written in Cyrillic, the other in Roman). There is reason to believe (e.g., Evett \& Humphreys, 1981) that the letter positions in a word or pseudoword may not be of equal status in priming situations. We elaborate on this notion below.

For simplicity, consider three-letter stimuli. Four kinds of context-target-word sequences can be identified: $\mathrm{ABC}-$ $A B C$ (identity); $X B C-A B C$ (initial different); $A X C$ $\mathrm{ABC}$ (middle different); and $\mathrm{ABX}-\mathrm{ABC}$ (final different). In each situation, the context activates a number of word units. The word unit corresponding to the context is activated fully; other word units are activated partially. These partially activated units have some of the same letters and/or phonemes in the same positions as the context word. Included among them, therefore, will be the unit corresponding to the target. By all accounts, the identity situation produces the largest priming effect, and an effect that is positive. Presumably, this is because the context $\mathrm{ABC}$ fully activates the word unit that is used in the lexical decision on the target $A B C$. In the three different situations (initial, middle, and final), the context activates partially the target unit, and the resulting priming effect is less than maximal and not necessarily positive (e.g., Experiment 1). We propose the following hypothesis: The activity level of a partially activated word-processing unit depends on which parts of the unit are activated. More specifically, we propose that the automatic activation of 
the word-processing unit corresponding to $\mathrm{ABC}$ is least during the processing of $\mathrm{XBC}$, most during the processing of $\mathrm{ABX}$, and intermediate during the processing of AXC. (From the point of view of information theory, activation of a word unit's initial phoneme relative to the other phonemes resolves most of the uncertainty concerning the question of which word was presented.) Simply speaking, if the phonemic similarity effect depends on how the target's representation is prepared by the context, then the effect should differ across initial-different, middledifferent, and final-different context-target sequences.

In Experiment 2, we used five-letter stimuli comprising consonants $(\mathrm{C})$ and vowels $(\mathrm{V})$ in the pattern CVCVC. According to the hypothesis just advanced, we expected a difference in phonemic similarity effects between context-target sequences that shared all but the initial $\mathrm{C}$ and context-target sequences that shared all but the middle $C$. In addition, in Experiment 2, we examined the potential side effect of stimulus-presentation order. Lexical decision on the target word of a given context-target pair could be influenced by the preceding stimulus pair. Although such an outcome was considered unlikely, prudence suggested that its significance be evaluated.

\section{Method}

Subjects. Forty-four high school seniors from the Fourth Belgrade Gymnasium were paid to serve in Experiment 2. Each subject was assigned to one of four groups according to his or her appearance at the laboratory. The subjects of the first two groups participated in Version A of this experiment, and the subjects of the other two groups participated in Version B.

Materials. Sixty-four word-word pairs were selected that were phonemically and, if written in the same alphabet, graphemically similar. All words were of the type CVCVC. To be considered phonemically similar, they could differ by only one letter. Word pairs were chosen so that this different letter was the middle consonant in 32 pairs and the initial consonant in the remaining 32 pairs. As in Experiment 1, contexts and targets were chosen to be identical with respect to accent position (i.e., syllable) and type (i.e., short rising, short falling, long rising, or long falling), and without any obvious associative or semantic relationship. All words were singular nominative nouns (masculine and feminine), as in Experiment 1 . Sixty-four pseudoword targets were derived from the word targets by changing the one consonant that was different from the context (so that pseudowords could also be considered to be derived from the contexts).

There were two kinds of pairs that differed in middle consonant and two kinds of pairs that differed in initial consonant (see Table 4). One member of each pair was transcribed in Cyrillic and the other in Roman, so all pairs were graphemically dissimilar. Consequently, for both initial-different and middle-different pairs, contexts and targets were: phonemically similar and graphemically dissimilar (Type 2, as defined in Table 1) and phonemically dissimilar and graphemically dissimilar (Type 4). The two types of pairs occurred with both word and pseudoword targets to make a total of eight stimulus groups with 16 stimuli per group.

Design. A given context was seen by an individual subject twice, once preceding the word target and once preceding the derived pseudoword target. A given subject never encountered a target word or pseudoword in any of the pairs more than once, but every subject saw every type of pair, and every target appeared in every type of pair. These constraints were met with two counterbalancing lists of 128 experimental stimulus pairs. Each list was prepared in two versions ( $A$ and $B$ ) that were distinguished only by the pseudorandom
Table 4

Examples of Context-Target Pairs Used in Experiments 2, 3, and 6 in which Members Differ Either in the Initial Phoneme or in a Phoneme Near the Middle

\begin{tabular}{|c|c|c|c|}
\hline \multicolumn{2}{|c|}{ Target } & \multicolumn{2}{|c|}{ Context Word } \\
\hline Word & Pseudoword & Type 2* & Type 4* \\
\hline \multicolumn{4}{|c|}{ Initial } \\
\hline $\begin{array}{l}\text { KUVAR } \\
\text { NAČIN }\end{array}$ & $\begin{array}{l}\text { GUVAR } \\
\text { FACIIN }\end{array}$ & $\begin{array}{l}\text { ЧУВАР } \\
\text { ЗАЧИН }\end{array}$ & $\begin{array}{l}\text { ЗАЧИН } \\
\text { ЧУВАР }\end{array}$ \\
\hline $\begin{array}{l}\text { ЖИВАЦ } \\
\text { РЕПІИҺ }\end{array}$ & $\begin{array}{l}\text { ЂИВАЦ } \\
\text { ЊЕЛИ' }\end{array}$ & $\begin{array}{l}\text { LIVAC } \\
\text { ČEPIĆ }\end{array}$ & $\begin{array}{l}\text { CEPIĆ } \\
\text { LIVAC }\end{array}$ \\
\hline \multicolumn{4}{|c|}{ Middle } \\
\hline $\begin{array}{l}\text { PUŽIĆ } \\
\text { RACUN }\end{array}$ & $\begin{array}{l}\text { PUDIĆ } \\
\text { RAŽUN }\end{array}$ & $\begin{array}{l}\text { ПУТИҺ } \\
\text { РАКУН }\end{array}$ & $\begin{array}{l}\text { РАКУН } \\
\text { ПУТЙ }\end{array}$ \\
\hline $\begin{array}{l}\text { ЛИКЕР } \\
\text { БУХАЧ }\end{array}$ & $\begin{array}{l}\text { ЛИГЕР } \\
\text { БУЛЬАЧ }\end{array}$ & $\begin{array}{l}\text { LIDER } \\
\text { BUKAČ }\end{array}$ & $\begin{array}{l}\text { BUKAČ } \\
\text { LIDER }\end{array}$ \\
\hline
\end{tabular}

* The type of context-target pair (identified in Table 1) that is produced by pairing the given context word with the target.

serial order of the same stimulus pairs: Those stimulus pairs that were adjacent on List $\mathbf{A}$ were not adjacent on List B, and vice versa. Thus, Experiment 2 consisted of "twins" (Version A and B) that were run intermittently. The experimental sequence was preceded by 40 practice pairs.

Procedure. The procedure was the same as in Experiment 1.

\section{Results and Discussion}

A four-way analysis of variance (stimulus-presentation order $\times$ lexicality $\times$ position $\times$ phonemic similarity) was computed using subjects as units. Neither the main effect of stimulus-presentation order (Version A vs. Version B) nor any interaction with presentation order proved significant. Given this fact, the latency and error data were collapsed over the presentation-order variable. Resulting mean latencies, standard deviations, and errors for both words and pseudowords are presented in Table 5. A threeway analysis was conducted on latencies and errors with

Table 5

Mean Decision Latencies ( $L$; in msec) and

Error Rate (ER; in \%), with the Corresponding Standard Deviation by Subjects and by Items in Experiment 2

\begin{tabular}{|c|c|c|c|c|}
\hline \multirow{3}{*}{$\begin{array}{c}\text { Position of } \\
\text { Different Phoneme }\end{array}$} & \multicolumn{4}{|c|}{ Phonemic Relation } \\
\hline & \multicolumn{2}{|c|}{ Similar } & \multicolumn{2}{|c|}{ Dissimilar } \\
\hline & $\mathrm{L}$ & ER & $\mathrm{L}$ & ER \\
\hline \multicolumn{5}{|c|}{ Word Target } \\
\hline Initial & $\begin{array}{r}730^{*} \\
75 \dagger \\
70 \ddagger\end{array}$ & $\begin{array}{l}3.69 \\
5.34 \\
6.87\end{array}$ & $\begin{array}{r}785 \\
71 \\
88\end{array}$ & $\begin{array}{r}7.39 \\
4.15 \\
15.39\end{array}$ \\
\hline Middle & $\begin{array}{r}805 \\
70 \\
87\end{array}$ & $\begin{array}{l}5.68 \\
5.07 \\
7.21\end{array}$ & $\begin{array}{r}778 \\
53 \\
76\end{array}$ & $\begin{array}{l}4.26 \\
5.59 \\
7.99\end{array}$ \\
\hline \multicolumn{5}{|c|}{ Pseudoword Target } \\
\hline Initial & $\begin{array}{r}805 \\
63 \\
67\end{array}$ & $\begin{array}{l}4.55 \\
5.17 \\
8.00\end{array}$ & $\begin{array}{r}821 \\
56 \\
66\end{array}$ & $\begin{array}{l}5.68 \\
7.19 \\
7.21\end{array}$ \\
\hline Middle & $\begin{array}{r}797 \\
48 \\
63\end{array}$ & $\begin{array}{l}2.84 \\
5.70 \\
4.86\end{array}$ & $\begin{array}{r}799 \\
57 \\
76\end{array}$ & $\begin{array}{l}2.84 \\
5.36 \\
5.86\end{array}$ \\
\hline
\end{tabular}

*Mean. † Standard deviation by subjects. $\ddagger$ Standard deviation by items. 
factors of lexicality, position (initial vs. middle), and phonemic similarity. The position variable is uninterpretable as a main effect. It includes the dissimilar control pairs (Type 4) that, by definition, are not constructed according to the initial-different or middle-different constraints that govern the phonemically similar pairs (Type 2). For the same reason, the interaction of position $\times$ lexicality cannot be given a meaningful interpretation. Position $x$ similarity, however, is readily interpreted and is a relation of major interest. Lexicality was significant $\left[\min F^{\prime}(1,112)=4.47, p<.05\right]$; similarity was not $\left[\min F^{\prime}(1,107)=1.73, p>.05\right]$. Position $\times$ similarity was significant $\left[\min F^{\prime}(1,107)=6.27, p<.01\right]$. For initial-different pairs, the similarity effect was $+36 \mathrm{msec}$, meaning that the target was facilitated; for middledifferent pairs, the similarity effect was $-12 \mathrm{msec}$, meaning that the target was inhibited. Also interpretable and of major interest is the dependence of the interaction of position $\times$ similarity on lexicality $\left[\min F^{\prime}(1,85)=3.82\right.$, $p<.05]$. No effects were significant in the error analysis.

The word error and latency data, and the pseudoword error and latency data, were analyzed separately with factors of position and similarity. The only significant outcome was the important interaction in the word latency data between similarity and position (initial different, similarity effect $=+55 \mathrm{msec}$ vs. middle different, similarity effect $=-27 \mathrm{msec})\left[\min F^{\prime}(1,77)=9.81, p<.01\right]$.

Thus, phonemic similarity effects depend on which parts of the context and target are shared. Sharing all but the initial consonant resulted in a positive similarity effect; sharing all but the middle consonant resulted in a negative similarity effect, as in Experiment 1 . The effect of position was more noticeable for words than for pseudowords. The results are consistent with the idea that the activity level of a partially activated word unit depends on which parts of the unit are activated. They are also consistent with the results of Experiment 1 in demonstrating that the observed similarity effects, for either type of phonemic similarity, were produced by shared phonemes and not by orthographic or form similarity. In Experiment 2, one member of each context-target pair was transcribed in Cyrillic, the other in Roman. In sum, the results of Experiments 1 and 2 suggest that the observed similarity effects with Serbo-Croatian words occurred because phonological information was extracted automatically from the contexts and that this affected lexical decisions on subsequent phonologically related targets.

The difference between the positive and the negative similarity effects may not, however, be simply a matter of a difference in the position of the unshared phoneme. A negative phonemic similarity effect has been reported by Colombo (1986) for Italian context-target pairs of the type CALMO-PALMO. A negative phonemic similarity effect is said by Colombo to be consistent with models in which inhibition among word-processing units is a major mechanism for selecting the most likely unit among the many physically similar candidates activated by a given word stimulus (e.g., McClelland \& Rumelhart, 1981; Rumelhart \& McClelland, 1982). It has been suggested that Colombo obtained a negative phonemic similarity effect rather than a positive phonemic similarity effect because she failed to use a masking stimulus forward of the context (Forster, 1987; Forster, Davis, Schoknecht, \& Carter, 1987). A positive phonemic similarity effect is repeatedly demonstrated for orthographicaliy similar English words in the lexical decision task when the context is subject to forward masking (e.g., Forster et al., 1987). Moreover, Colombo (1986) found that the negative phonemic similarity effect was tied to targets of high frequency. Low-frequency targets reversed the sign.

\section{EXPERIMENT 3}

In Experiment 3, we focus on the dependence of the phonemic similarity effect on the frequency of the target word as reported by Colombo (1986). Lexical decisions on high-frequency targets were found to be slower in a rhyming context than in a nonrhyming context; the opposite was the case for low-frequency targets. In Experiment 3 , we manipulated target frequency but did so in the form of experiential familiarity (Gernsbacher, 1984). Subjective ratings of word familiarity are obviously more contemporary than are printed frequency counts. They also are probably more representative of word experiences given that they take into account words spoken, written, and heard. Although such ratings will vary with populations, such variation is immaterial when the ratings are provided by people from the same population as the subjects in the experiment. Such was the case in Experiment 3 and the subsequent experiments in the present article using familiarity as a variable. The distinct advantage, in experimental terms, of using an experiential familiarity measure is that it is a more reliable predictor of response latency and accuracy in word-recognition experiments than are printed frequency counts (Gernsbacher, 1984).

Target familiarity was investigated in Experiment 3 in connection with a further examination of the effect of manipulating the position of the letter (middle or initial) distinguishing a target word from its phonemically similar context.

\section{Method}

Subjects. Twenty-two high school seniors from the Fourth Belgrade Gymnasium were paid to serve in Experiment 3. Each subject was assigned to one of four counterbalancing groups according to his or her appearance at the laboratory. After all subjects had been run, it was found that one of them was not a native speaker of Serbo-Croatian. This subject's data were excluded from analyses.

Materials. Sixty-four word-word pairs were selected that were phonemically similar. To be considered phonemically similar, they could differ by only one letter. Word pairs were chosen so that this different letter was the middle consonant in 32 pairs and the initial consonant in the remaining 32 pairs. In addition, word pairs were chosen so that half of them contained targets of high familiarity and half of them contained targets of low familiarity. The words were drawn from the upper and lower ends of a set of 120 words judged for familiarity on a 5 -point scale $(5=$ very familiar. 
$1=$ very unfamiliar) by 35 students from the same year as the high school students who served as subjects. The individual familiarity judgments were summed up for each word at each level of the 5-point scale. As in the previous experiments, contexts and targets were chosen to be identical with respect to accent position and type and without any obvious associative or semantic relationship. As in Experiment 2 , all words were singular nominative nouns (masculine and feminine), with two syllables and five letters. Sixty-four pseudoword targets were derived from the word targets by changing the one consonant that was different from the context.

For both initial-different and middle-different pairs, as illustrated in Table 4, contexts and targets were: (1) phonemically similar and graphemically dissimilar (Type 2), and (2) phonemically and graphemically dissimilar (Type 4). These two types occurred for both word and pseudoword targets.

Design. A given context was seen by an individual subject twice, once preceding the word target and once preceding the derived pseudoword target. A given subject never encountered a target word or pseudoword in any of the pairs more than once, but every subject saw every type of pair, and every target appeared in every type of pair. These constraints were met with two counterbalancing groups. In total, each subject saw 128 experimental stimulus pairs ordered randomly. The experimental sequence was preceded by 32 practice pairs of the same types.

Procedure. The procedure was the same as in Experiment 1.

\section{Results and Discussion}

Table 6 presents the mean reaction times, standard deviations, and errors for words and pseudowords. An analysis of variance was conducted on all data with factors of lexicality, position, and phonemic similarity. Position as a main effect, and its interaction with lexicality, are not interpretable for the reasons cited in Experiment 2. In the latencies analysis, phonemic similarity was not significant $\left[\min F^{\prime}(1,129)=1.8, p>.05\right]$; lexicality was significant $\left[\min F^{\prime}(1,104)=8.0, p<.01\right]$. The important interaction between phonemic similarity and position was significant $\left[\min F^{\prime}(1,116)=6.96, p<.01\right.$; for initial position, similarity effect $=+35 \mathrm{msec}$; for middle

Table 6

Mean Decision Latencies $(L$; in $\mathrm{msec})$ and

Error Rate (ER; in \%), with the Corresponding Standard Deviation by Subjects and by Items in Experiment 3

\begin{tabular}{|c|c|c|c|c|}
\hline \multirow{3}{*}{$\begin{array}{c}\text { Position of } \\
\text { Different Phoneme }\end{array}$} & \multicolumn{4}{|c|}{ Phonemic Relation } \\
\hline & \multicolumn{2}{|c|}{ Similar } & \multicolumn{2}{|c|}{ Dissimilar } \\
\hline & $\mathrm{L}$ & ER & $\mathrm{L}$ & ER \\
\hline \multicolumn{5}{|c|}{ Word Target } \\
\hline Initial & $\begin{array}{r}689 * \\
110 \dagger \\
61 \ddagger\end{array}$ & $\begin{array}{l}5.36 \\
5.33 \\
9.64\end{array}$ & $\begin{array}{r}731 \\
106 \\
79\end{array}$ & $\begin{array}{l}6.25 \\
7.91 \\
7.30\end{array}$ \\
\hline Middle & $\begin{array}{r}730 \\
122 \\
48\end{array}$ & $\begin{array}{r}6.25 \\
7.40 \\
11.67\end{array}$ & $\begin{array}{r}718 \\
123 \\
72\end{array}$ & $\begin{array}{l}3.87 \\
4.63 \\
6.29\end{array}$ \\
\hline \multicolumn{5}{|c|}{ Pseudoword Target } \\
\hline Initial & $\begin{array}{r}743 \\
101 \\
40\end{array}$ & $\begin{array}{l}4.76 \\
7.37 \\
9.57\end{array}$ & $\begin{array}{r}771 \\
90 \\
62\end{array}$ & $\begin{array}{l}3.57 \\
4.67 \\
5.77\end{array}$ \\
\hline Middle & $\begin{array}{r}745 \\
85 \\
53\end{array}$ & $\begin{array}{l}2.08 \\
3.61 \\
0.00\end{array}$ & $\begin{array}{r}739 \\
99 \\
53\end{array}$ & $\begin{array}{l}1.10 \\
2.51 \\
2.50\end{array}$ \\
\hline
\end{tabular}

*Mean. †Standard deviation by subjects. $¥$ Standard deviation by items.
Table 7

Mean Word Decision Latencies ( $L$; in msec) and Error Rate (ER; in \%), as a Function of Target Familiarity, with the Corresponding Standard Deviation by Subjects and by Items in Experiment 3

\begin{tabular}{|c|c|c|c|c|c|}
\hline \multirow{3}{*}{$\begin{array}{l}\text { Position } \\
\text { of Different } \\
\text { Phoneme }\end{array}$} & \multirow{3}{*}{$\begin{array}{c}\text { Target } \\
\text { Familiarity }\end{array}$} & \multicolumn{4}{|c|}{ Phonemic Relation } \\
\hline & & \multicolumn{2}{|c|}{ Similar } & \multicolumn{2}{|c|}{ Dissimilar } \\
\hline & & L & ER & L & ER \\
\hline \multirow[t]{6}{*}{ Initial } & Low & $706^{*}$ & 8.93 & 787 & 9.52 \\
\hline & & $126 \dagger$ & 9.80 & 123 & 11.80 \\
\hline & & $91 \ddagger$ & 10.28 & 83 & 10.72 \\
\hline & High & 672 & 1.79 & 679 & 2.98 \\
\hline & & 105 & 4.48 & 101 & 6.74 \\
\hline & & 46 & 5.04 & 34 & 4.62 \\
\hline \multirow[t]{6}{*}{ Middle } & Low & 750 & 8.93 & 771 & 4.76 \\
\hline & & 126 & 12.59 & 133 & 7.37 \\
\hline & & 50 & 12.07 & 40 & 6.24 \\
\hline & High & 712 & 3.57 & 664 & 2.98 \\
\hline & & 125 & 5.79 & 119 & 6.74 \\
\hline & & 50 & 6.92 & 32 & 4.62 \\
\hline
\end{tabular}

*Mean. †Standard deviation by subjects. $¥$ Standard deviation by items.

position, similarity effect $=-9 \mathrm{msec}]$. There was no three-way interaction $\left(\min F^{\prime}<1\right)$. In the error analysis, only lexicality reached significance $\left[\min F^{\prime}(1,85)=4.24\right.$, $p<.05]$.

To incorporate target familiarity, a second analysis was performed on the word data with factors of target familiarity, phonemic similarity, and position. The relevant data are presented in Table 7. We consider the latencies first. Familiarity was significant (high $=706 \mathrm{msec}$ vs. low $=$ $731 \mathrm{msec})\left[\min F^{\prime}(1,78)=37.16, p<.001\right]$, but phonemic similarity was not $\left[\min F^{\prime}(1,77)=1.61, p>.05\right]$. The two phonemic similarity interactions proved significant: similarity $\times$ familiarity (for high familiarity, similarity effect $=-21 \mathrm{msec}$; for low familiarity, similarity effect $=+51 \mathrm{msec})\left[\min F^{\prime}(1,73)=9.59, p<.01\right]$ and phonemic similarity $\times$ position (for initial position, similarity effect $=+42 \mathrm{msec}$; for middle position, similarity effect $=-12 \mathrm{msec})\left[\min F^{\prime}(1,76)=6.56, p<.01\right]$. There was no three-way interaction $\left(\min F^{\prime}<1\right)$. The error analysis found only the main effect of familiarity to be significant $\left[\min F^{\prime}(1,55)=6.93, p<.01\right]$.

The present results confirm that the effect of phonemic similarity varies as a function of which phonemes are shared. The effect is positive when all phonemes but the initial phoneme are shared, and negative when all phonemes but the middle phoneme are shared. The same pattern had been observed in Experiment 2, and the latter aspect had been observed in Experiment 1. In addition, the present results concur with those of Colombo (1986) in showing that the familiarity of the target determines the sign of the phonemic similarity effect; it is negative when the familiarity is high, and it is positive when the familiarity is low.

How might the dependence of the phonemic similarity effect on target familiarity be explained? In consensus with Colombo (1986), we believe that the answer lies with activation assumptions that McClelland and Rumelhart 
(1981, pp. 379-381) incorporated into their network model of word recognition. Three assumptions are of relevance. First, the units for high-frequency words have resting levels higher than those for low-frequency words, so that, for the same stimulation, representations of highfrequency words are activated sooner. Second, inactive units have no influence on their neighbors. Only units in an active state have any effects, either excitatory or inhibitory. Third, the net input to a unit drives the activation of the unit up or down, depending on whether it is positive or negative. The degree of the effect of the input on the unit is modulated by the unit's current activity level to keep the input to the unit from driving it beyond some maximum and minimum values (Grossberg, 1978). This means that the inhibition felt by a word unit is dependent on its level of activation. The latter assumption will be referred to as Grossberg's principle of self-modulation. Let us apply the preceding assumptions to phonemically similar and dissimilar context-target sequences.

A phonemically similar context word will activate partially a number of word units-namely, those that have some of the same phonemes in the same positions as the context word. One of these partially activated word units represents the target. If the target is a high familiarity word, the activation level of its representation will be relatively high and, by Grossberg's principle of selfmodulation, the amount of inhibition that its representation receives from other units during the processing of the context word will also be relatively high. Consequently, when the target word does occur it is processed in circumstances in which its corresponding word unit is significantly inhibited, thereby slowing the target's recognition. A phonemically dissimilar context, in contrast, would not activate the target's representation. The target's representation would not, therefore, be subject to inhibition prior to the occurrence of the target. In sum, target processing should be slower in phonemically similar contexts.

Colombo's (1986) argument, as we have stated it thus far, predicts that the phonemic similarity effect should always be negative, with the magnitude of this negative effect proportional to a target's familiarity. However, in her work, and in the data of the present experiment, phonemically similar contexts with low-familiarity targets produced positive similarity effects. One way to accommodate this result is to require that a given word unit is subject to inhibition only when its activation level exceeds a criterial value (Colombo, 1986). If word units representing low-familiarity targets do not reach this criterion, they will tend to escape inhibition. They will, however, benefit from being activated above the resting level by the occurrence of a phonemically similar context. Consequently low-familiarity targets, with all the benefits of activation and none of the costs of inhibition, will be responded to faster in phonemically similar contexts than in phonemically dissimilar contexts. There is a better way, however, to accommodate the facilitation with low-familiarity targets, one that dispenses with the need to assume a further specialized mechanism. A phonemically similar context activates levels of units below the word-unit level that will be used in the processing of the target. Letter and/or phoneme units to be used in processing the target are primed, and these primed units are sources of activation for the word unit to be used in processing the target. Other things being equal, these activations induced by the phonemically similar context would guarantee a facilitation of the response to the target. Apparently, in the case of highfamiliarity targets, the inhibition generated at the wordunit level exceeds the excitation generated below, whereas, in the case of low-familiarity targets, it does not.

In Colombo's (1986) studies, similarity and lexicality tended to interact. In conditions in which the sign of the similarity effect was negative for words, it was positive for pseudowords. If a negative similarity effect is due strictly to inhibition of word units, it should not occur for pseudowords. Consider a word context-pseudoword target sequence. A context word produces activation at prelexical levels (e.g., letter, phoneme), as well as at the word-unit level. Word units activated to a certain level begin to inhibit other word units. The set of activated word units sends activation, but no inhibition, to the adjacent prelexical level; in McClelland and Rumelhart's (1981) model, inhibition operates only within a level. That some word units are inhibited at the time of presentation will not affect the speed of processing a target pseudoword. In contrast, the fact that some prelexical units are activated by the context (namely, those that will be involved in the processing of the target pseudoword) can influence the speed of processing a target pseudoword. Accordingly, the phonemic similarity effect for pseudoword targets, like that for low-familiarity words, should be positive. In the data of Experiment 3, however, the phonemic similarity effect was clearly positive only for initial-different pseudowords. For middle-different pseudowords, the numerical difference between phonemically similar and phonemically dissimilar conditions was small and negative. In Experiment 1, it was also the case that middle-different pseudowords failed to behave in the manner expected of and observed in low-familiarity words. The pseudoword data from Experiment 2 are more compatible with expectations, but they fall short of providing confirmation. We should note, however, that the predicted similarity $\times$ lexicality interaction was observed in a subsequent experiment (Experiment 9).

With respect to the position variable, we hypothesized above that the activation level of a partially activated word unit depends on which parts are activated. Specifically, we suggested that a context that differs from a target in the initial letter/phoneme position may activate the target's representation less than a context that differs in the middle letter/phoneme position. The general hypothesis and the specific suggestion can be accommodated by the preceding arguments. Let us return to the example of context-target sequences of three-letter stimuli. Consider the initial-different sequence $\mathrm{XBC}-\mathrm{ABC}$ and the middledifferent sequence $\mathrm{AXC}-\mathrm{ABC}$. The context $\mathrm{XBC}$ will ac- 
tivate the word unit $\mathrm{ABC}$ to the level of $a_{i}$. In comparison, the context $\mathrm{AXC}$ will activate the word unit $\mathrm{ABC}$ to the level $a_{m}$, where $a_{m}>a_{i}$ by argument. Because a unit's activation level is a significant determinant of the degree to which the unit is inhibited, then $A B C$ will be inhibited more in the AXC context than in the XBC context. Furthermore, if $a_{i}$ is sufficiently small so that the inhibition generated from units at the word-unit level fails to exceed the excitation generated from units below the word-unit level, then the $\mathrm{XBC}-\mathrm{ABC}$ sequence will produce a positive phonemic similarity effect.

\section{EXPERIMENT 4}

In Experiment 4, we extend to contextual items our study of familiarity's contribution to the phonemic similarity effect. Consider phonemically similar pairs comprising target words of high familiarity. Whether the context is a high- or a low-familiarity word, the target's representation should be inhibited and a negative similarity effect should be observed. Similarly, context familiarity would not be expected to affect the sign of the similarity effect for low-familiarity targets. Regardless of context frequency, the word units representing low-familiarity words should receive relatively little inhibition. This means that, for a high- or low-familiarity context followed by a low-familiarity target, the processing advantages of priming units below the word-unit level should outweigh the processing disadvantages of inhibiting the target's word unit. In sum, we expect to see a similarity $\times$ targetfamiliarity interaction but not a similarity $\times$ contextfamiliarity interaction.

Although context familiarity should not influence the similarity effect, it should be present as a main effect, and it might be expected to interact with target familiarity. The activation level of the representation of a highfamiliar context will be greater than that of a low-familiar context at the time of target presentation. If the lexical decision process is understandable ultimately as a signaldetection problem, then decision speed and accuracy will vary inversely with the signal (activity level of target word unit)-to-noise (activity levels of other word units) ratio. This ratio would be smaller, on the average, for highfamiliarity contexts. Additionally, the signal-to-noise hypothesis suggests that there should be an interaction of context familiarity and target familiarity: This ratio should be smallest for the combination of high-familiarity contexts and low-familiarity targets and largest for the combination of low-familiarity contexts and high-familiarity targets.

Experiment 4 also extends the investigation of similarity type or, more precisely, the pattern of phonemic similarity between context and target. In the previous experiments, a phonemically similar context and target were distinguished by the middle or initial letter. In the present experiment, context and target in the phonemically similar condition were distinguished by the final letter. We hypothesized above that a context that differs from the target in the final phoneme position may activate the tar- get's representation more than a context that differs in the middle position. Because a unit's activation level, by Grossberg's (1978) self-modulation principle, modulates the degree to which the unit is inhibited, the target $\mathrm{ABC}$ should be inhibited more in the $A B X$ context than in the AXC context. We should expect, therefore, that the $\mathrm{ABX}-\mathrm{ABC}$ (final different) word sequences will produce a negative phonemic similarity effect.

\section{Method}

Subjects. Twenty high school seniors from the Fourth Belgrade Gymnasium were paid to serve in Experiment 4. Each subject was assigned to one of four counterbalancing groups according to his or her appearance at the laboratory.

Materials. One hundred twenty-five pairs of words were created that differed only in the final consonant letter. Examples are given in Table 8. All words were between four and six letters in length; a context word always had the same number of phonemes as its corresponding target word. The individual words in these pairs then were presented for familiarity judgments to 35 high school students from the same school and the same year as the students who participated as subjects in the experiment. As before, a 5-point scale was used. Words ranked 1 to 3 on the average were designated as low familiarity, and words ranked 4 to 5 on the average were designated as high familiarity. On the basis of these judgments, 96 pairs were drawn from the original 125 pairs. Twenty-four pairs were selected such that the mean familiarity measure for the context items was between 1 and 3 , and the mean familiarity measure for the target items was between 4 and 5 . This pattern defined the low context-high target group of stimuli. The same procedure was used to arrive at the other three groupings involving word targets: low context-low target, high context-high target, and high context-low target. To create the corresponding word-pseudoword pairings, the final letters of the targets were changed. To create the phonemically dissimilar pairs, contexts were interchanged among the original (phonemically similar) pairs within each of the four word-target and four pseudoword-target groupings. There were in all, therefore, 16 groupings of stimuli. All other features of the context-target pairs were as in the preceding experiments.

Design. The 8 word-word and the 8 word-pseudoword conditions were manipulated within subjects. No subject saw the same target twice, and the targets that appeared in each condition were counterbalanced over subjects. This was achieved for the 8 word-word groupings and the 8 word-pseudoword groupings by reversing context words within pairs of a given grouping of stimuli for half of the subjects. Each subject was presented with 12 stimuli pairs in each of the 16 conditions for a total of 192 pairs.

Procedure. The procedure was the same as in Experiment 1.

\section{Results and Discussion}

Table 9 presents the mean latencies, standard deviations, and errors for words and pseudowords. Two sets

Table 8

Examples of Context-Target Pairs Used in Experiments 4 and 7 in which Members Differ in the Final Phoneme

\begin{tabular}{|c|c|c|c|}
\hline \multicolumn{2}{|c|}{ Target } & \multicolumn{2}{|c|}{ Context Word } \\
\hline Word & Pseudoword & Type 2* & Type $4^{*}$ \\
\hline GUSAN & GUSAD & ГУСАР & ФАКИН \\
\hline FAKIR & FAKIŽ & ФАКИН & ГУСАР \\
\hline ПАСЉ & ПАСУФ & PASUS & DUVAC \\
\hline ДУВАН & ДУВАГ & DUVAČ & PASUS \\
\hline
\end{tabular}

* The type of context-target pair (identified in Table 1) that is produced by pairing the given context word with the target. 
Table 9

Mean Decision Latencies ( $\mathrm{L}$; in msec) and Error Rate (ER; in \%), with the Corresponding Standard Deviation by Subjects and by Items in Experiment 4

\begin{tabular}{ccccr} 
& \multicolumn{4}{c}{ Phonemic Relation } \\
\cline { 2 - 4 } Context & \multicolumn{2}{c}{ Similar } & \multicolumn{2}{c}{ Dissimilar } \\
\cline { 2 - 5 } Familiarity & L & ER & L & ER \\
\hline \multirow{4}{*}{ High } & $738^{*}$ & 11.25 & 709 & 8.96 \\
& $91 \dagger$ & 6.77 & 96 & 5.28 \\
& $100 \ddagger$ & 17.09 & 106 & 16.40 \\
Low & 697 & 3.96 & 683 & 4.79 \\
& 95 & 6.41 & 97 & 5.45 \\
& 79 & 7.07 & 92 & 11.11 \\
& & Pseudoword Target & & \\
High & 757 & 3.12 & 807 & 3.13 \\
& 92 & 4.85 & 102 & 4.25 \\
& 69 & 7.19 & 81 & 6.24 \\
Low & 770 & 3.34 & 780 & 3.75 \\
& 114 & 4.99 & 102 & 4.66 \\
& 86 & 5.95 & 90 & 9.14 \\
\hline
\end{tabular}

*Mean. †Standard deviation by subjects. $\ddagger$ Standard deviation by items.

of analyses were conducted. The first was performed on the latencies and errors of both the word and the pseudoword data, ignoring target familiarity since this variable was undefined for pseudoword targets. The second was limited to the word data.

The factors in the first analysis were lexicality, phonemic similarity, and context familiarity. Lexicality was significant (words $=707 \mathrm{msec}$ vs. pseudowords $=$ $779 \mathrm{msec})\left[\min F^{\prime}(1,62)=23.27, p<.001\right]$, as was context familiarity (high $=753 \mathrm{msec} v \mathrm{ss}$. low $=733 \mathrm{msec}$ ) $\left[\min F^{\prime}(1,165)=4.15, p<.05\right]$. Phonemic similarity was insignificant as a main effect (similar $=741 \mathrm{msec}$ vs. dissimilar $=745 \mathrm{msec})\left(\min F^{\prime}<1\right)$, but interacted significantly with lexicality (word similarity effect $=$ $-22 \mathrm{msec}$ vs. pseudoword similarity effect $=+31 \mathrm{msec}$ ) $\left[\min F^{\prime}(1,194)=7.14, p<.01\right]$. In contrast, the interaction of similarity with context familiarity was not significant $\left(\min F^{\prime}<1\right)$. Context familiarity $\times$ lexicality also failed to reach significance $\left[\min F^{\prime}(1,123)=2.4\right.$, $p>.05]$. The error analysis confirmed the insignificance of similarity $\left(\min F^{\prime}<1\right)$ and the significance of lexicality (words $=7.24 \%$ vs. pseudowords $=3.33 \%$ ) $\left[\min F^{\prime}(1,95)=7.15, p<.01\right]$ and the significance of context familiarity (high $=6.61 \%$ vs. low $=3.96 \%$ ) $\left[\min F^{\prime}(1,164)=4.24, p<.05\right]$. Only one interaction in the error analysis reached significance, namely, lexicality $\times$ context familiarity $\left[\min F^{\prime}(1,120)=4.93, p<\right.$ .05 ; for words, high $=10.10 \%$, and low $=4.38 \%$; for pseudowords, high $=3.13 \%$ and low $=3.54 \%$ ]. All other interactions yielded $\min F^{\prime}$ values of less than 1 .

Because of the interactions with lexicality, a separate analysis was performed on the pseudoword data with the same three factors. These show that the majority of effects observed in the overall analysis were due to the word data (which are addressed in the second set of analyses).
Thus, only phonemic similarity proved significant for pseudoword latencies $\left[\min F^{\prime}(1,77)=4.96, p<.05\right]$.

The word analyses were conducted with factors of similarity, context familiarity, and target familiarity. The data are summarized in Table 10 . Considering latencies, the two familiarities were both significant [for context, $\min F^{\prime}(1,111)=7.68, p<.01 ;$ for target, $\min F^{\prime}(1,84)$ $=29.41, p<.001]$. Similarity was not significant $\left[\min F^{\prime}(1,111)=2.57, p>.05\right]$, but its interaction with target familiarity was significant $\left[\min F^{\prime}(1,72)=4.65\right.$, $p<.05]$. For high-familiarity targets, phonemic similarity effect was negative (similar $=693 \mathrm{msec}$ vs. dissimilar $=644 \mathrm{msec}$ ). For low-familiarity targets, the similarity effect was numerically positive (similar $=744 \mathrm{msec}$ vs. dissimilar $=752 \mathrm{msec}$ ). Notably, neither the interaction of similarity and context familiarity nor the interaction of context familiarity and target familiarity were significant $\left(\min F^{\prime}<1\right.$ ). Considering errors, again both familiarity variables were significant [for context, $\min F^{\prime}(1,103)=6.78, p<.01 ;$ for target, $\min F^{\prime}(1,107)$ $=16.24, p<.001]$. Similarity was again insignificant $\left(\min F^{\prime}<1\right)$. The error analysis did reveal an interaction between context and target familiarity $\left[\min F^{\prime}(1,109)=\right.$ $4.45, p<.05$ ], as can be clearly seen from inspection of Table 10. When target familiarity was high, context familiarity did not make a difference to response accuracy (high context $=3.54 \%$, low context $=2.29 \%$ ); when target familiarity was low, context familiarity affected response accuracy (high context $=16.67 \%$, low context $=6.46 \%$ ).

In summary, the results of Experiment 4 agree largely with expectations. First, the average phonemic similarity effect was negative for words, whereas it was positive for pseudowords. This outcome agrees with the hypothesis that the negative phonemic similarity effect is linked to inhibitory processes acting on word units. Second, the similarity effect with words was negative for high target familiarity $(-49 \mathrm{msec})$ and tended, at least numer-

Table 10

Mean Word Decision Latencies ( $L$; in msec) and Error Rate (ER; in \%), with the Corresponding Standard Deviation by Subjects and by Items in Experiment 4

\begin{tabular}{|c|c|c|c|c|c|}
\hline \multirow{2}{*}{\multicolumn{2}{|c|}{ Word Familiarity }} & \multicolumn{4}{|c|}{ Phonemic Relation } \\
\hline & & \multicolumn{2}{|c|}{ Similar } & \multicolumn{2}{|c|}{ Dissimilar } \\
\hline Context & Target & L & ER & L & ER \\
\hline High & High & $\begin{array}{r}712 * \\
90 \dagger \\
68 \ddagger\end{array}$ & $\begin{array}{l}4.17 \\
6.34 \\
5.84\end{array}$ & $\begin{array}{r}658 \\
93 \\
53\end{array}$ & $\begin{array}{l}2.92 \\
4.89 \\
4.64\end{array}$ \\
\hline Low & High & $\begin{array}{r}674 \\
92 \\
82\end{array}$ & $\begin{array}{l}2.97 \\
6.77 \\
4.64\end{array}$ & $\begin{array}{r}631 \\
91 \\
53\end{array}$ & $\begin{array}{l}1.67 \\
4.36 \\
3.81\end{array}$ \\
\hline High & Low & $\begin{array}{l}768 \\
100 \\
115\end{array}$ & $\begin{array}{l}18.27 \\
10.68 \\
21.40\end{array}$ & $\begin{array}{l}764 \\
114 \\
108\end{array}$ & $\begin{array}{r}15.01 \\
9.21 \\
21.26\end{array}$ \\
\hline Low & Low & $\begin{array}{r}721 \\
112 \\
68\end{array}$ & $\begin{array}{l}5.00 \\
7.84 \\
8.85\end{array}$ & $\begin{array}{r}741 \\
116 \\
88\end{array}$ & $\begin{array}{r}7.92 \\
8.32 \\
14.74\end{array}$ \\
\hline
\end{tabular}

*Mean. $†$ Standard deviation by subjects. $\ddagger$ Standard deviation by items. 
ically, to be positive for low target familiarity $(+8 \mathrm{msec})$. The manipulation of phonemic similarity in Experiment 4 was on the final letter (MINUS-MINUT), in contrast to initial and middle letters in preceding experiments. A tentative conclusion is that a difference in final letters, like a difference in middle letters, is more apt to produce a negative phonemic similarity effect than is a difference in initial letters. Third, the similarity effect was independent of context familiarity. This was expected on the hypothesis that the inhibition on the target generated in the processing of a phonemically similar context depends on the activation level of the target, which depends significantly on the familiarity of the target.

As expected, high context familiarity slowed responses to the target and produced more errors relative to low context familiarity. This effect of context familiarity was independent of the context-target similarity relation. The outcome was expected on the basis of the assumption that context familiarity exerts its influence on postlexical processes. The expected interaction of context familiarity and target familiarity was found for errors but not for latencies.

\section{EXPERIMENT 5}

For Serbo-Croatian, it has been argued that the pronunciations of printed/written words are based on the states of phoneme-processing units that are activated from below by letter-processing units and activated from above by word-processing units (Lukatela, Turvey, et al., 1989). We wish to develop the argument that, because of this property, phonemic similarity effects with naming should be (1) positive for all types of phoneme similarity, (2) identical for words and pseudowords, and (3) indifferent to the familiarity of the target. The outcome for lexical decision has been that phonemic similarity effects are negative or positive, depending on type of similarity and target frequency, and that they may differ for words and pseudowords.

According to our model (Lukatela, Turvey, et al., 1989), there are, in ascending order, feature-, letter-, phoneme-, and word-processing units. Within-level interactions are only inhibitory. Between-level interactions are excitatory and occur in both directions only for adjacent levels. For present purposes, the most significant aspect of the model is the level of phoneme units. One reason is that the assembly of a pronunciation is based on the states of the phoneme-processing units. Second, phonemeprocessing units activate word-processing units and are affected, in turn, by the word-processing units through feedback connections. In other words, the lexicon is accessed phonologically and orthographically.

Let us consider what happens to phoneme units and word units in the case of a phonemically similar context and target, such as DUVAN ("tobacco," Roman)ДУЋАН ("shop," Cyrillic). The context DUVAN will activate one phoneme unit to a high level at each letter position. Other phoneme units will be activated partially for each letter position. These variously activated pho- neme units will activate word units. Many word units will be activated partially. The size of the partially activated set is determined by the number of words that share aspects of DUVAN's phonemic structure. Lateral inhibition trims the set, leaving just those word units that fit most closely DUVAN. Eventually, the word unit representing DUVAN will dominate, with the other candidate word units, including that representing the high frequency ДУЋАН, inhibited. As this competition among the word units takes place, the phoneme units receive downward activation from the word units. Gradually, the phoneme units most activated from below (letter-unit level) will be the ones most activated from above (word-unit level). If naming is based on the states of phoneme units, then naming ДУЋАН will benefit from the prior occurrence of DUVAN; DUVAN primes all but one of the phoneme units from which ДУЋАН's name is constructed. In contrast, if lexical decision is based on the states of word units, then lexically evaluating the high-frequency word ДУЋАН should suffer from the prior occurrence of DUVAN; DUVAN inhibits the word unit whose activity level eventually governs the decision that ДУЋАН is a word.

Models of English-word recognition often exclude a level of phoneme-processing units (e.g., Aaronson \& Ferres, 1983; Baron, 1973; Becker, 1976, 1979; Kolers, 1970; Paap, Newsome, McDonald, \& Schvaneveldt, 1982; Smith, 1971). The idea is that the phonology of English words is derived from the lexicon and not prelexically, as advocated above for Serbo-Croatian words. A model that excludes a phoneme-unit level makes different predictions about the phonemic similarity effect for naming. Most notably, it predicts that the similarity effect for naming should be qualitatively similar to the phonemic similarity effect for lexical decision. Negative similarity effects should be observed, target familiarity should affect the sign of the effect, and the similarity effect may differ for words and pseudowords. These predictions follow largely from the fact that, for a model without phoneme-processing units, the activity levels of word units govern the speed of naming. Thus, the familiarity of a target in a phonemically similar context will determine whether or not the activation level of its lexical representation at the time of target presentation is above or below the resting level.

Experiment 5 examines the phonemic similarity effect in naming for context-target sequences that differ in the middle letter. It is basically a replication of Experiment 1 with the exception of the dependent measure. Our model leads us to expect a positive phonemic similarity effect for both words and pseudowords, and independence of the effect from graphemic similarity.

\section{Method}

Subjects. Fifty-two high school seniors from the Fifth Belgrade Gymnasium were paid to serve in the experiment. Each subject was assigned to one of four counterbalancing groups according to his or her appearance at the laboratory.

Materials and Design. These were the same as in Experiment 1. 
Table 11

Mean Naming Latencies ( $L$; in msec) and Error Rate (ER; in \%), with the Corresponding Standard Deviation by Subjects and by Items in Experiment 5

\begin{tabular}{lcccr}
\hline & \multicolumn{4}{c}{ Phonemic Relation } \\
\cline { 2 - 5 } Alphabet & \multicolumn{2}{c}{ Similar } & \multicolumn{2}{c}{ Dissimilar } \\
\cline { 2 - 5 } Same & L & ER & L & ER \\
& $647^{*}$ & 1.82 & 662 & 2.03 \\
& $89 \dagger$ & 3.77 & 87 & 3.97 \\
Other & $63 \ddagger$ & 3.53 & 58 & 3.65 \\
& 641 & 1.39 & 659 & 3.10 \\
& 82 & 2.88 & 91 & 4.18 \\
& 56 & 3.73 & 61 & 4.77 \\
Same & & Pseudoword Target & & \\
& 687 & 1.60 & 711 & 2.56 \\
& 109 & 2.98 & 126 & 3.56 \\
Other & 59 & 4.27 & 74 & 5.16 \\
& 698 & 2.78 & 727 & 2.78 \\
& 102 & 4.19 & 114 & 3.33 \\
& 70 & 5.82 & 69 & 4.13 \\
\hline
\end{tabular}

* Mean. † Standard deviation by subjects. ‡Standard deviation by items.

Procedure. Subjects were required to pronounce each target letter string as quickly and distinctly as possible. In all conditions, latencies from the onset of the target to the onset of the response were measured by a voice operated trigger relay. Naming was considered to be erroneous when the pronunciation included a phoneme not specified by the characters in the letter string, the pronunciation was not smooth (i.e., the subject hesitated after beginning the name), or the response was not initiated within the cut-off latency. All presentation parameters and cut-off latencies were the same as in Experiment 1.

\section{Results and Discussion}

The mean latencies, standard deviations, and errors for words and pseudowords are presented in Table 11. As can be seen in Table 11, phonemic similarity was facilitatory of both word- and pseudoword-naming times, independent of graphemic similarity. An analysis of variance was conducted on the latency data with factors of lexicality, phonemic similarity, and alphabet (same vs. other). Both similarity (similar $=668 \mathrm{msec}$ vs. dissimilar $=690 \mathrm{msec}$ ) and lexicality (words $=652 \mathrm{msec} v$ s. nonwords $=706 \mathrm{msec}$ ) were significant $\left[\min F^{\prime}(1,176)=\right.$ $11.67, p<.001$, and $\min F^{\prime}(1,187)=38.64, p<.001$, respectively]. Alphabet was not significant $\left(\min F^{\prime}<1\right)$, and the important interactions of similarity $\times$ alphabet $\left(\min F^{\prime}=1\right)$ and similarity $\times$ lexicality were not significant $\left(\min F^{\prime}<1\right)$. Also insignificant was the alphabet $\times$ lexicality interaction $\left(\min F^{\prime}<1\right)$. Repeating the analysis for errors produced no effects, with all $\min F^{\prime}$ values less than 1 .

\section{EXPERIMENT 6}

The novelty of Experiment 5, and the contrary nature of its results with respect to those of the preceding lexical decision experiments, encouraged a replication. Experiment 6 repeats the design of Experiment 5, with the additional manipulation of the type of phonemic similarity. It will be recalled that, in the lexical decision experiments, similarity effects depended on the position of the different phoneme. These position-dependent outcomes were attributed to processes at the level of word units. According to our model of Serbo-Croatian word recognition, they should not be present in rapid naming.

\section{Method}

Subjects. Forty-four high school seniors from the Fifth Belgrade Gymnasium were paid to serve in Experiment 6. Each subject was assigned to one of four counterbalancing groups according to his or her appearance at the laboratory.

Materials. Sixty-four word-word pairs were chosen with the same restrictions as in Experiment 1, except that half differed by the first consonant and half differed by (approximately) the middle consonant (see Table 1). Sixty-four word-pseudoword pairs were generated from word targets in the standard way. The experimental sequence was divided into quarters, each preceded by four practice trials of a similar sort following a brief rest. Context-target pairs were ordered randomly within each quarter.

Design. A given subject saw 128 experimental and 16 practice trials. Four lists were counterbalanced as in Experiment 1.

Procedure. The procedure was the same as in Experiment 5

\section{Results and Discussion}

A four-way analysis of variance (position $\times$ lexicality $x$ phonemic similarity $x$ alphabet) was computed using subjects as units. Neither the main effect of position (initial vs. middle) nor any interaction with position proved significant. Given this fact, the latency and error data were collapsed over the position variable. Resulting mean latencies, standard deviations, and errors for words and pseudowords are presented in Table 12. As can be seen in Table 12 , phonemic similarity was facilitatory of both wordand pseudoword-naming times, independent of graphemic similarity. An analysis of variance was conducted on the

Table 12

Mean Naming Latencies ( $L$; in msec) and Error Rate (ER; in \%), with the Corresponding Standard Deviation by Subjects and by Items in Experiment 6

\begin{tabular}{lcccc}
\hline & \multicolumn{4}{c}{ Phonemic Relation } \\
\cline { 2 - 5 } Alphabet & \multicolumn{2}{c}{ Similar } & \multicolumn{2}{c}{ Dissimilar } \\
\cline { 2 - 5 } of Context & L & ER & L & ER \\
\hline \multirow{4}{*}{ Same } & \multicolumn{3}{c}{ Word Target } \\
& $567^{*}$ & 3.69 & 580 & 2.41 \\
& $74 \dagger$ & 4.73 & 79 & 3.62 \\
Other & $49 \ddagger$ & 5.30 & 56 & 5.43 \\
& 571 & 3.35 & 587 & 3.69 \\
& 77 & 4.35 & 79 & 5.44 \\
& 53 & 6.19 & 43 & 6.42 \\
Same & & Pseudoword Target & & \\
& 605 & 6.68 & 620 & 7.39 \\
& 86 & 7.67 & 93 & 6.91 \\
& 48 & 7.81 & 54 & 9.70 \\
Other & 614 & 6.53 & 636 & 7.67 \\
& 90 & 7.38 & 106 & 6.85 \\
& 55 & 9.37 & 68 & 10.27 \\
\hline
\end{tabular}

* Mean. † Standard deviation by subjects. $\ddagger$ Standard deviation by iterns. 
latency data with factors of lexicality, phonemic similarity, and alphabet. Both similarity (similar $=589 \mathrm{msec}$ vs. dissimilar $=605 \mathrm{msec}$ ) and lexicality (words $=576 \mathrm{msec}$ vs. nonwords $=619 \mathrm{msec}$ ) were significant $\left[\min F^{\prime}(1,149)\right.$ $=8.80, p<.01$, and $\min F^{\prime}(1,169)=32.57, p<$ .001 , respectively]. Importantly, neither alphabet nor the interaction of similarity $\times$ lexicality were significant $\left[\min F^{\prime}(1,164)=3.18, p>.05\right.$, and $\min F^{\prime}<1$, respectively]. Repeating the analysis for errors produced one significant effect, namely, lexicality $\left[\min F^{\prime}(1,116)=\right.$ $15.94, p<.001]$. For all other effects, $\min F^{\prime}<1$. In sum, Experiment 6 replicated the results of Experiment 5: With rapid naming as the response, the phonemic similarity effect was positive for both words and pseudowords and was indifferent to graphemic similarity. In addition, the effect of type of phonemic similarity found in the previous lexical decision experiments was not found in Experiment 6. Results suggest that the naming of SerboCroatian words is based on the states of processing units that are prior to word units (prelexical) and subsequent to letter units. In accordance with our model (Lukatela, Turvey, et al., 1989), naming depends on the states of phoneme-processing units. The next experiment provides further verification of this claim.

\section{EXPERIMENT 7}

Experiment 7 examines the contribution of context familiarity and target familiarity to the phonemic similarity effect in naming. In addition, it examines the significance of phonemic similarity defined by distinguishing context and target stimuli by the final letter. Experiment 7 is a naming replication of Experiment 4 in which lexical decision was the dependent measure. In Experiment 4, phonemic similarity interacted with lexicality and with target familiarity, but not with context familiarity. The two familiarities were significant main effects in Experiment 4, but an interaction between them was only evident in the error analysis. Our model predicts that, with naming speed and accuracy as the dependent measures, (1) the phonemic similarity effect should be positive for both words and pseudowords, (2) it should be independent of both target familiarity and context familiarity, and (3) there should be no main effect of context familiarity.

In lexical decision, the arguments marshaled by Colombo (1986), and developed above in reference to Serbo-Croatian language materials, identify target frequency or familiarity as the major determinant of the sign of the phonemic similarity effect. We proposed that a phonemically similar context will partially activate the word unit of the target because of phonemic similarity, and that the target's word unit will become inhibited if the target is a high-frequency (familiarity) word and will escape inhibition if the target is a low-frequency (familiarity) word. As a consequence, the effect of phonemic similarity in lexical decision is negative for high-frequency words and positive for low-frequency words.
The account of naming in Serbo-Croatian claims that naming is based on the states of the phoneme-processing units and not on the states of the word-processing units. To repeat the example of DUVAN-ДУЋАН from above, although the word unit of the high-familiarity word ДУЋАН (meaning "shop") is inhibited in the processing of DUVAN, the phoneme units corresponding to the letters $Д, Y, A$, and $H$ are highly activated. The same degree of phoneme-unit facilitation would be expected if the target in a phonemically similar context-target sequence was a low-familiarity word (or a pseudoword). Consequently, if naming is based on the states of the phoneme-processing units, target familiarity should not affect the similarity effect observed when words are named.

Let us now turn to context familiarity. The main effect of context familiarity in lexical decision observed in Experiment 4 was attributed to postlexical processes. Relative to a context word of low familiarity, a context word that is of high familiarity affects the postlexical decision process by reducing the signal-to-noise ratio given by the target's activity level relative to the level of other highly active units. This postlexical binary decision process based on relative signal strength is absent from naming (Carello et al., 1988; Seidenberg et al., 1984). Consequently, no main effect of context familiarity is expected. An interaction between target familiarity and context familiarity would follow from the fact that the signal-to-noise ratio varies with the familiarity of the target relative to the familiarity of the context. This interaction expected for lexical decision is not expected for naming, again for the reason that naming does not involve postlexical decision processes.

\section{Method}

Subjects. Twenty-two high school seniors from the Fourth Belgrade Gymnasium were paid to serve in Experiment 7. Each subject was assigned to one of four counterbalancing groups according to his or her appearance at the laboratory.

Materials and Design. Same as in Experiment 4.

Procedure. Same as in Experiment 5.

\section{Results and Discussion}

Table 13 presents the mean latencies, standard deviations, and errors for words and pseudowords. Two sets of analyses were conducted. The first was performed on the latencies and errors of both the word and pseudoword data. Target familiarity was ignored since this variable was undefined for pseudoword targets. The second was limited to the word data.

The analyses performed on all data had factors of lexicality, phonemic similarity, and context familiarity. For both latencies and errors, lexicality proved significant $\left[\min F^{\prime}(1,102)=32.78, p<.001\right.$, and $\min F^{\prime}(1,77)=$ $7.64, p<.01$, respectively]. Similarly, for both latencies and errors, phonemic similarity proved significant $\left[\min F^{\prime}(1,68)=18.05, p<.001(\right.$ similar $=605 \mathrm{msec}$ vs. dissimilar $=635 \mathrm{msec})$; and $\min F^{\prime}(1,112)=4.70$, $p<.05$ (similar $=2.94 \%$ vs. dissimilar $=4.92 \%)$, re- 
Table 13

Mean Naming Latencies ( $L$; in msec) and Error Rate (ER; in \%), with the Corresponding Standard Deviation by Subjects and by Items in Experiment 7

\begin{tabular}{crcrr}
\hline & \multicolumn{3}{c}{ Phonemic Relation } \\
\cline { 2 - 5 } Context & \multicolumn{2}{c}{ Similar } & \multicolumn{2}{c}{ Dissimilar } \\
\cline { 2 - 4 } Familiarity & L & ER & L & ER \\
\hline \multirow{3}{*}{ High } & & Word Target & & \\
& $579 *$ & 2.65 & 605 & 3.60 \\
& $65 \dagger$ & 2.42 & 74 & 3.47 \\
Low & $45 \ddagger$ & 4.95 & 55 & 6.95 \\
& 588 & 1.89 & 620 & 2.08 \\
& 75 & 2.48 & 79 & 3.58 \\
& 42 & 4.18 & 44 & 4.29 \\
High & Pseudoword Target & & \\
& 628 & 3.79 & 648 & 7.58 \\
& 82 & 3.84 & 99 & 6.38 \\
Low & 60 & 7.46 & 65 & 12.06 \\
& 624 & 3.41 & 668 & 6.44 \\
& 82 & 3.99 & 96 & 4.01 \\
& 50 & 5.51 & 53 & 7.25 \\
\hline
\end{tabular}

* Mean. + Standard deviation by subjects. $\ddagger$ Standard deviation by items.

spectively]. The main effect of context familiarity was not significant for either latencies or errors. Considering latencies, only the phonemic similarity $\times$ context-familiarity interaction exceeded a $\min F^{\prime}$ value of $1\left[\min F^{\prime}(1,138)\right.$ $=1.62, p>.05$ ]. In all other cases, for both latencies and errors, interactions proved nonexistent $\left(\min F^{\prime}<1\right)$.

The word analysis had factors of phonemic similarity, context familiarity, and target familiarity. Table 14 summarizes the data. Considering latencies, the main effects of phonemic similarity and target familiarity were significant: For phonemic similarity (similar $=583 \mathrm{msec}$ vs. dissimilar $=613 \mathrm{msec})\left[\min F^{\prime}(1,86)=12.95, p<\right.$ .001 ]; for target familiarity (high $=590 \mathrm{msec}$ vs. low $=606 \mathrm{msec})\left[\min F^{\prime}(1,112)=4.73, p<.05\right]$. Context familiarity was insignificant $\left[\min F^{\prime}(1,110)=2.31, p>\right.$

Table 14

Mean Word Naming Latencies (L; in msec) and Error Rate (ER; in \%), with the Corresponding Standard Deviation by Subjects and by Items in Experiment 7

\begin{tabular}{|c|c|c|c|c|c|}
\hline \multirow{2}{*}{\multicolumn{2}{|c|}{ Word Familiarity }} & \multicolumn{4}{|c|}{ Phonemic Relation } \\
\hline & & \multicolumn{2}{|c|}{ Similar } & \multicolumn{2}{|c|}{ Dissimilar } \\
\hline Context & Target & $\mathrm{L}$ & ER & $\mathrm{L}$ & ER \\
\hline High & High & $\begin{array}{r}574 * \\
64 \dagger \\
44 \ddagger\end{array}$ & $\begin{array}{l}2.27 \\
3.80 \\
4.83\end{array}$ & $\begin{array}{r}598 \\
78 \\
53\end{array}$ & $\begin{array}{l}1.52 \\
3.29 \\
3.46\end{array}$ \\
\hline Low & High & $\begin{array}{r}582 \\
78 \\
44\end{array}$ & $\begin{array}{l}1.89 \\
3.57 \\
3.77\end{array}$ & $\begin{array}{r}606 \\
85 \\
43\end{array}$ & $\begin{array}{l}2.27 \\
4.59 \\
4.02\end{array}$ \\
\hline High & Low & $\begin{array}{r}584 \\
68 \\
46\end{array}$ & $\begin{array}{l}3.03 \\
4.10 \\
5.13\end{array}$ & $\begin{array}{r}612 \\
75 \\
58\end{array}$ & $\begin{array}{l}5.68 \\
6.99 \\
8.81\end{array}$ \\
\hline Low & Low & $\begin{array}{r}594 \\
74 \\
40\end{array}$ & $\begin{array}{l}1.89 \\
3.57 \\
4.63\end{array}$ & $\begin{array}{r}635 \\
82 \\
41\end{array}$ & $\begin{array}{l}1.89 \\
3.57 \\
4.63\end{array}$ \\
\hline
\end{tabular}

*Mean. †Standard deviation by subjects. $\ddagger$ Standard deviation by items.
.05 ] There were no interactions. In all cases, $\min F^{\prime}<$ 1. Considering errors, there were no main effects and no interactions; only context familiarity $\times$ target familiarity exceeded a $\min F^{\prime}$ value of $1\left[\min F^{\prime}(1,94)=1.92\right.$, $p>.05]$.

We predicted that the effect of phonemic similarity would be the same for both words and pseudowords, as observed in Experiments 5 and 6. This prediction was satisfied in Experiment 7. More importantly, we predicted that the similarity effect would be indifferent to target familiarity and context familiarity and that context familiarity would not be a significant main effect. These predictions were also upheld. The results imply that naming Serbo-Croatian letter strings (1) is largely immune to the actual states of word-processing units and the inhibitory relations among them and (2) does not engage postlexical processes. Point 1 does not deny lexical factors in naming. Rather, it underscores the view that the wordunit level is not the level of fundamental significance to naming.

\section{EXPERIMENT 8}

The data of Experiments 5, 6, and 7 support the central role of phoneme-processing units in assembling the pronunciation of a Serbo-Croatian word or pseudoword (Lukatela, Turvey, et al., 1989). The states of the phoneme-processing units depend upon activation from the letter-processing units below and activation from the word-processing units above. We now identify two features of the Serbo-Croatian language that reflect an important contribution of word-processing units to the naming of words. As noted in the introduction, there are words whose pronunciations cannot be derived unequivocally from the letter-to-phoneme correspondences. Given the presence of letters that are assigned different phonemes in the two alphabets, the automatically realized connections between individual letters and individual phonemes will yield a number of possible pronunciations at the phoneme-unit level. The level of word units contains the information needed to specify uniquely the pronunciation of phonologically ambiguous words. Within the proposed model for Serbo-Croatian word perception and naming, the equivocality is resolved through the automatic twoway interaction of phoneme- and word-processing units (Lukatela, Turvey, et al., 1989).

The second feature of the Serbo-Croatian language implicating a significant role for word-processing units in naming is the fact that the stress pattern is not marked in the orthography. The majority of Serbo-Croatian words display a standard accentuation pattern with stress on the first syllable. The minority are stressed on the second syllable. Moreover, the stress can be either long or short, rising or falling. Pronouncing a Serbo-Croatian word requires knowledge of its stress pattern. That knowledge is not given through the letter-units-to-phoneme-units connections. It is only made available by accessing word- 
processing units. Below, we suggest how the model for Serbo-Croatian word perception can be modified to incorporate stress information in naming.

In Experiments 1-7, the context and target words were phonologically unambiguous. All were stressed on the first syllable, and the stress was of the same type in both context and target. Consider one such sequence, the context BALON (balloon) and the target BARON (baron). The phoneme units $/ \mathrm{b} /, / \mathrm{a} /, / \mathrm{o} /$, and $/ \mathrm{n} / \mathrm{shared}$ by both words would be activated by BALON's presentation. These aspects were spelled out above. We now add the assumption that phoneme units that receive and are activated by stimulation are connected to phoneme units that guide articulation, and that the connections between the two kinds of phoneme units are realized automatically: If the input phoneme unit $/ b /$ is activated (above threshold), the output phoneme unit $/ b /$ will be activated similarly. As a consequence of the aforementioned connections, BALON's presentation primes the articulation of BARON by priming most of the required output phoneme units that are connected, in turn, to units of articulation (see Jordan, 1986).

There is a further way in which we assume that BALON primes BARON's pronunciation. BALON activates its word unit and, thereby, activates information about its stress pattern. This information propagates from the word unit down to the articulatory units activated by BALON's phonemic constituents. As a result, a stress pattern appropriate to the pronunciation of BARON is defined over articulatory units that are similar in kind to those comprising the pronunciation of BARON (specifically, the articulatory unit for $/ a /$ is assigned a short accent). In addition to this short-term articulatory encoding bias, there is a long-term articulatory encoding bias. Because of the strong bias in the language to first-syllable stress, it can be assumed that the assembly of a pronunciation is biased similarly. Stress on the first syllable is the default option.

In Experiment 8, the stress pattern of the context and target never concur. They disagree on place of stress and/or manner of stress (long vs. short, rising vs. falling). In half of the sequences, as in Experiments 5, 6, and 7 , the context and target are phonemically similar letter strings. Thus, with respect to assembling the target's pronunciation, the context will activate (1) the appropriate output phonemes and inappropriate stress on one half of the trials and (2) irrelevant output phonemes and in- appropriate stress on the other half of the trials. According to the arguments presented above, in Situation 1, pronouncing the target requires changing the stress pattern on a previously activated articulatory unit. In Situation 2, pronouncing the target requires activating the appropriate articulatory units and assigning the appropriate stress. If changing the stress pattern consumes much more time than is gained by sensitizing articulatory units, then naming in Situation 1 should be slower than naming in Situation 2; if changing stress consumes much less time than is gained through priming, then Situation 1 should be faster.

\section{Method}

Subjects. Fifty-two high school seniors from the Fifth Belgrade Gymnasium were paid to serve in Experiment 8. Each subject was assigned to one of four counterbalancing groups according to his or her appearance at the laboratory.

Materials. Fifty-six word-word pairs of Types 1, 2, 3, and 4 (types are defined in Table 1) were chosen as in Experiment 1, but, this time, they were chosen to be different in either type of accent (rising or falling, long or short) or location of accent (first or second syllable). Examples are given in Table 15. Words could be of two, three, or four syllables. They comprised 6.25 phonemes on average (compared to 5.38 phonemes on average in Experiment 1). Fifty-six word-pseudoword pairs were constructed as detailed previously.

Design. Each subject saw 112 experimental and 32 practice pairs ( 8 before each quarter of the experimental list), counterbalanced as in Experiment 1.

Procedure. Same as in Experiment 4.

\section{Results and Discussion}

The data are shown in Table 16. An analysis of the latency data using the factors of phonemic similarity, alphabet, and lexicality found only a main effect of lexicality $\left[\min F^{\prime}(1,147)=30.65, p<.001\right]$. The main effects of phonemic similarity and alphabet were insignificant, as were all interactions $\left(\min F^{\prime}<1\right)$. The same was true of the error analysis: For lexicality $\left[\min F^{\prime}(1,156)=12.0, p<.001\right]$; and for all other main effects and interactions $\left(\min F^{\prime}<1\right)$.

A comparison of Tables 11 and 12 with Table 16 shows that nonuniformity in the stress patterns of context and target words eliminated the phonemic similarity effect in naming. In terms of the hypotheses advanced above, changing stress (either its length or its position) consumed more time than was gained by priming the appropriate

Table 15

Examples of Context-Target Pairs Used

in Experiments 8 and 9 in which Members Differ in Stress Pattern

\begin{tabular}{|c|c|c|c|c|c|}
\hline \multicolumn{2}{|c|}{ Target } & \multicolumn{4}{|c|}{ Context Word } \\
\hline Word & Pseudoword & Type $1 b^{*}$ & Type 3* & Type $2 b^{*}$ & Type 4* \\
\hline $\begin{array}{l}\text { MAŠINA } \\
\text { GITASRA }\end{array}$ & $\begin{array}{l}\text { MAZINA } \\
\text { GETARA }\end{array}$ & $\begin{array}{l}\text { MALINA } \\
\text { GATARA }\end{array}$ & $\begin{array}{l}\text { GATARA } \\
\text { MALINA }\end{array}$ & $\begin{array}{l}\text { МАЛИНА } \\
\text { ГАТАРА }\end{array}$ & $\begin{array}{l}\text { ГАТАРА } \\
\text { МАЛИНА }\end{array}$ \\
\hline $\begin{array}{l}\text { БУљИНА } \\
\text { ПІОЛИЦА }\end{array}$ & $\begin{array}{l}\text { ЊУЉИНА } \\
\text { ЖОЛИЦА }\end{array}$ & $\begin{array}{l}\text { ДУЉИНА } \\
\text { КОЛИЦА }\end{array}$ & $\begin{array}{l}\text { КОЛИЦА } \\
\text { ДУЈИНА }\end{array}$ & $\begin{array}{l}\text { DULJINA } \\
\text { KOLICA }\end{array}$ & $\begin{array}{l}\text { KOLICA } \\
\text { DULINA }\end{array}$ \\
\hline
\end{tabular}

* The type of context-target pair (identified in Table 1) that is produced by pairing the given context word with the target. Stressed vowels are underlined. 
Table 16

Mean Naming Latencies (L; in msec) and Error Rate (ER; in \%), with the Corresponding Standard Deviation by Subjects and by Items in Experiment 8

\begin{tabular}{|c|c|c|c|c|}
\hline \multirow[b]{3}{*}{ Alphabet } & \multicolumn{4}{|c|}{ Phonemic Relation } \\
\hline & \multicolumn{2}{|c|}{ Similar } & \multicolumn{2}{|c|}{ Dissimilar } \\
\hline & $\mathrm{L}$ & ER & $\mathrm{L}$ & ER \\
\hline \multicolumn{5}{|c|}{ Word Target } \\
\hline Same & $624^{*}$ & 16.81 & 603 & 11.12 \\
\hline & $77 t$ & 11.39 & 63 & 8.88 \\
\hline & $71 \ddagger$ & 17.67 & 61 & 14.59 \\
\hline \multirow[t]{3}{*}{ Other } & 621 & 16.54 & 620 & 13.80 \\
\hline & 64 & 10.15 & 76 & 11.95 \\
\hline & 59 & 17.69 & 59 & 15.96 \\
\hline \multicolumn{5}{|c|}{ Pseudoword Target } \\
\hline \multirow[t]{3}{*}{ Same } & 669 & 6.46 & 675 & 9.75 \\
\hline & 72 & 7.11 & 78 & 9.39 \\
\hline & 66 & 8.14 & 84 & 13.32 \\
\hline \multirow[t]{3}{*}{ Other } & 681 & 10.22 & 676 & 9.89 \\
\hline & 84 & 8.17 & 77 & 11.85 \\
\hline & 88 & 11.84 & 85 & 12.68 \\
\hline
\end{tabular}

* Mean. † Standard deviation by subjects. $¥$ Standard deviation by items.

articulatory units. For example, if MALINA (meaning "raspberry") was the context, with short, rising stress on the first /a/, and MAŚINA (meaning "machine") was the target, with long, rising stress on $/ \mathrm{i} /$, then (1) the articulatory units of relevance to MASINA (namely, those corresponding to $/ \mathrm{m} /, / \mathrm{a} /, / \mathrm{i} /, / \mathrm{n} /$, and $/ \mathrm{a} /$ in $1 \mathrm{st}$, 2nd, 4th, 5th, and 6th positions, respectively) would be primed, and (2) /a/ in the 2 nd position would be stressed. The data suggest that the benefits of (1) are lost by the requirements to shift stress from /a/ in the 2 nd position to /i/ in the 4th position and to change the stress type from short to long.

The mixing of first- and second-syllable stressed contexts affected the relation between phonemic similarity and the latency to name pseudowords. How is the result with pseudowords to be understood? When the pseudoword MAZINA is presented, it will activate partially a number of word units, including MALINA and MAS̆INA. Because no word unit is fully activated, and because those that are activated partially are stressed either on the first or second syllable, competition will ensue among word units with respect to the assignment of stress to MAZINA. The nature and time course of this competition would be the same for both phonemically similar and dissimilar contexts. Assuming that the time to assemble a pronunciation is scaled, in part, to the time to determine a stress pattern, then it can be supposed that the delay induced by the competitive process is enough to eliminate the advantage of phonemic similarity. That is, even though the articulatory units for MAZINA are prepared faster in a phonemically similar context than in a phonemically dissimilar context, the resolution of stress assignment takes the same amount of time in both contexts. If activating articulatory units and assigning them intensity weights are independent, parallel activities, then a slow assignment will override a swift activation. Importantly, the foregoing situation should not arise in the conditions of Experiments 5,6 , and 7 . There, the pseudowords would activate word units that would be uniform in their stress pattern (accented first syllable). Consequently, no competition with regard to stress assignment would ensue.

In approximately $80 \%$ of the phonemically similar pairs, the names given to pseudoword targets were stressed as their contexts. In the phonemically dissimilar pairs, target stress was not systematically related to context stress. One implication of these facts is that the competition at the word level was generally unresolved, with the stress assignment going by default, in the phonemically similar situation, to the stress determined by the immediately preceding context. In the phonemically dissimilar situations, the stress of the context played no major, systematic role in the assembling of the target's pronunciation. It appears that stress is defined with respect to particular articulatory units. If the context and target do not share these units, then the stress pattern of the context is irrelevant to the eventual pronunciation of the target.

One other feature of the pseudoword data is valuable to understanding the naming of Serbo-Croatian words. We divided the target stimuli in the phonemically similar pairs into those preceded by a context stressed on the first syllable (the standard way) and those preceded by a context stressed on the second syllable. In first-syllable contexts the target latency was $669 \mathrm{msec}$, on the average; in second-syllable contexts the latency was $700 \mathrm{msec}$, on the average. This difference is consistent with our hypothesis that the assembling of a pronunciation "prefers" the standard stress pattern.

\section{EXPERIMENT 9}

In our model of pronunciation assembly for SerboCroatian words, activated word units inform articulatory units about accent via a connective network. The incongruity of context and target in stress pattern is an effect at the level of articulatory units. In our view, lexical decision is based on the states of the word units and involves a postlexical decision that is constrained by the target unit's activity level relative to the level of other activated units. Thus, lexical decision does not engage the level of articulatory units. A lexical decision replication of Experiment 8 was conducted, therefore, with the expectation that stress incongruity between context and target should not affect the relation between phonemic similarity and decision latency. Experiment 9 uses context-target sequences that differ in middle phonemes. The results of Experiment 9, therefore, should be the same as the results of the first three experiments: A negative phonemic similarity effect should prevail for words and a less negative, or even a positive, phonemic similarity effect should prevail for pseudowords regardless of the context-target stress relationship. 


\section{Method}

Subjects. Forty-eight high school seniors from the Fifth Belgrade Gymnasium were paid to serve in Experiment 9. Each subject was assigned to one of four counterbalancing groups according to his or her appearance at the laboratory.

Materials, Design, and Procedure. Same as in Experiment 8, with the exception that targets were lexically evaluated instead of named.

\section{Results and Discussion}

Table 17 presents the mean latencies, standard deviations, and errors for words and pseudowords. Analysis of variance on the latency data revealed that the main effect of lexicality was significant $\left[\min F^{\prime}(1,116)=29.28\right.$, $p<.001]$ and that only the interaction between phonemic similarity and lexicality was significant $\left[\min F^{\prime}(1,149)=\right.$ $6.09, p<.01]$. For words, the phonemic similarity effect was $-24 \mathrm{msec}$; for pseudowords, the similarity effect was $+12 \mathrm{msec}$. The error analyses showed the significance of lexicality $\left[\min F^{\prime}(1,139)=5.43, p<.05\right]$; the errors were committed more to words than to pseudowords. The interaction between phonemic similarity and lexicality proved significant $\left[\min F^{\prime}(1,147)=4.06\right.$, $p<.05$ ]. For words, the phonemic similarity effect, in terms of errors, was $-2.16 \%$; for pseudowords, the phonemic similarity effect, in terms of errors, was $2.82 \%$. In sum, responses to words were slower and less accurate in phonemically similar pairs than in phonemically dissimilar pairs, with the opposite holding true for pseudowords. This outcome replicates the similarity $\times$ lexicality interaction reported by Colombo (1986) and necessitated by the claim that the negative similarity effect is due to interactions at the word-unit level. Furthermore, the results of Experiment 9 show that the differently signed phonemic similarity effects for words and pseudowords observed for lexical decision when context and target are stressed identically are preserved when context and tar-

Table 17

Mean Naming Latencies (L; in msec) and Error Rate (ER; in \%), with the Corresponding Standard Deviation by Subjects and by Items in Experiment 9

\begin{tabular}{lccrr}
\hline & \multicolumn{4}{c}{ Phonemic Relation } \\
\cline { 2 - 3 } Alphabet & L & ER & L & ER \\
\cline { 2 - 5 } Same & \multicolumn{4}{c}{ Word Target } \\
& $782^{*}$ & 9.88 & 754 & 8.33 \\
& $100 \dagger$ & 9.05 & 83 & 7.98 \\
Other & $75 \ddagger$ & 9.70 & 72 & 11.01 \\
& 790 & 10.63 & 771 & 6.99 \\
& 92 & 9.32 & 87 & 6.34 \\
& 81 & 12.36 & 72 & 10.98 \\
Same & & Pseudoword Target & & \\
& 823 & 4.76 & 839 & 8.93 \\
& 104 & 6.81 & 101 & 9.94 \\
Other & 60 & 6.13 & 68 & 11.11 \\
& 827 & 3.87 & 835 & 5.36 \\
& 103 & 5.70 & 98 & 7.29 \\
& 71 & 5.72 & 74 & 7.85 \\
\hline
\end{tabular}

*Mean. † Standard deviation by subjects. $\$$ Standard deviation by items. get are stressed differently. This outcome contrasts with that found for naming. The contrasting sensitivity to stress congruity can be attributed to the dominant roles played by phoneme and articulatory units in naming and by word units in lexical decision.

\section{EXPERIMENT 10}

The final experiment seeks stronger confirmation of the claim that the phonemic similarity effect in lexical decision is due to the automatic, prelexical activation of phonological information. Experiment 10 has three major features. First, phonemically similar contexts are presented very briefly under forward-masking conditions. This is done to minimize the explicit identification of the context but to still allow the context to influence the processing of the target. Such conditions may help to prevent intentional, strategic use of context information (e.g., Evett \& Humphreys, 1981; Humphreys et al., 1982). Second, each context differs from its target in alphabet and case. For example, if the target is in Cyrillic uppercase, then the context is in Roman lowercase. This manipulation exaggerates the graphemic dissimilarity between phonemically similar words. Third, pseudoword phonemically similar contexts are used. The reason for their incorporation is explained below.

Consider the argument from the introduction that there are two ways in which a word's phonology can be derived (Coltheart, 1978). One way is through the lexicon. Once a word unit has been activated on the basis of its orthographic properties, phonological information about the word is made available. The other way is through GPCs. Suppose that the lexical way is mandatory (automatic) and that the GPCs' way is optional (nonautomatic), as has been frequently proposed (e.g., Coltheart et al., 1977; Henderson, 1982). Then, under conditions that minimize optional strategies, only the lexical way should work. On the basis of the preceding argument, Humphreys et al. (1982) hypothesized that, "if phonological information is activated via a nonlexical route, a pseudohomophone priming effect should occur'" (p. 581). Finding that the pseudohomophone condition (tial-TILE) in their masking experiment did not differ from its graphemic control condition (tirl-TILE), Humphreys et al. (1982) concluded that the lexical way of deriving phonology (1) is the only one of the two that is automatic and (2). may be, in fact, the only route.

The present experiment used a subset of stimuli from Experiments 2 and 3 in which context and target differ in the initial letter (see Table 4). In Experiments 2 and 3 , the phonemic similarity effect for these initial different stimuli was positive for both word targets (Experiment 2, $+49 \mathrm{msec}$; Experiment 3, $+42 \mathrm{msec}$ ) and pseudoword targets (Experiment 2, $+30 \mathrm{msec}$; Experiment 3, $+28 \mathrm{msec}$ ). Experiment 10, therefore, used phonemic similarity conditions known to produce facilitation. Our objective was to create experimental conditions that would be comparable, at least in part, to those in the Humphreys 
et al. (1982) studies of the phonemic similarity effect in English. On the basis of our account of Serbo-Croatian word processing, we expect that, in Experiment 10, a pseudoword context that is phonemically similar to its target should facilitate lexical decision on the target. Furthermore, we expect that the phonemic similarity effect in pseudoword-word conditions should not differ from that in word-pseudoword conditions. If the phonemic similarity effect in the lexical decision task with graphemically dissimilar stimuli is due primarily to an automatic, prelexical computation of a letter string's phonology, then the phonemic similarity effect should not be affected by the lexical composition of the phonemically similar pair.

\section{Method}

Subjects. Forty-four high school seniors from the Fifth Belgrade Gymnasium were paid to serve in Experiment 10. Each subject was assigned to one of four counterbalancing groups according to his or her appearance at the laboratory.

Materials. Examples of the primary stimulus set are to be found in Table 4. The basic description of the types of words used in Experiment 2 applies to the words of the present experiment. As depicted in Table 4, a context and its target differed in the initial phoneme. However, all contexts were presented in lowercase, and all targets were presented in uppercase. The context and target in a pair never appeared in the same alphabet. In half of the pairs, the context was Cyrillic, and in the other half, it was Roman. There were 32 such word-word pairs. By changing the initial letter in the contexts, 32 pseudoword-word pairs were created; by chang ing the initial letter in the targets, 32 word-pseudoword pairs were created; by changing the initial letters in both contexts and targets, 32 pseudoword-pseudoword pairs were created. Phonemic similarity was manipulated only in the 32 pseudoword-word pairs ( 16 similar, 16 dissimilar) and in the 32 word-pseudoword pairs ( 16 similar, 16 dissimilar). The remaining 64 pairs provided filler items.

Design. There were four groups of subjects, 11 subjects per group. Each subject saw 16 pseudoword (PW)-word (W) rhyming pairs, $16 \mathrm{~W}-\mathrm{PW}$ rhyming pairs, $16 \mathrm{PW}-\mathrm{W}$ control pairs, and $16 \mathrm{~W}-\mathrm{PW}$ control pairs. A given context and a given target were seen by an individual subject only once. This was achieved as follows. Let A-B, $\mathrm{C}-\mathrm{D}, \mathrm{E}-\mathrm{F}$, and $\mathrm{G}-\mathrm{H}$ be four rhyming word pairs. For Group 1, these pairs are rearranged and individual members modified as follows: A*-B (phonemic similarity), A-D* (phonemic dissimilarity), $\mathrm{E}-\mathrm{F}^{*}$ (phonemic similarity), and $\mathrm{E}^{*}-\mathrm{H}$ (phonemic dissimilarity), where the asterisk identifies the pseudoword derived from the designated word by changing the initial letter; for Group 2, $\mathrm{C}^{*}-\mathrm{B}$ (phonemic dissimilarity), $C^{*}-D$ (phonemic similarity), G-F* (phonemic dissimilarity), and $\mathrm{G}-\mathrm{H}^{*}$ (phonemic similarity); and so on for Groups 3 and 4 . The foregoing procedure was repeated for all 16 subsets of four word-word pairs that made up the set of 64 wordword pairs. As a consequence, each subject in each group saw 16 pairs of each of the following: W-PW (phonemic similarity), W-PW (phonemic dissimilarity), PW-W (phonemic similarity), and PW-W (phonemic dissimilarity). The experimental sequences were preceded by 24 practice pairs of the same type.

Procedure. The procedure was the same as in previous experiments, with the following exception. The fixation point was fol lowed by a forward mask, consisting of a row of 10 hash marks, centered on the screen for $500 \mathrm{msec}$. This was followed immediately by the context for $80 \mathrm{msec}$ and, immediately after that, the target for $500 \mathrm{msec}$, both in the same location as the mask had been. A pretest with a different group of subjects had shown that the prime could not be reliably identified under these circumstances.
Table 18

Mean Decision Latencies (L; in msec) and Error Rate (ER; in \%), with the Corresponding Standard Deviation by Subjects and by Items in Experiment 10 with Masked, Graphemically Dissimilar Contexts

\begin{tabular}{|c|c|c|c|c|c|}
\hline \multirow[b]{3}{*}{ Context } & \multirow[b]{3}{*}{ Target } & \multicolumn{4}{|c|}{ Phonemic Relation } \\
\hline & & \multicolumn{2}{|c|}{ Similar } & \multicolumn{2}{|c|}{ Dissimilar } \\
\hline & & L & ER & $\mathrm{L}$ & ER \\
\hline Pseudoword & Word & $\begin{array}{r}748^{*} \\
82 \dagger \\
87 \ddagger\end{array}$ & $\begin{array}{l}6.25 \\
6.74 \\
8.24\end{array}$ & $\begin{array}{r}776 \\
81 \\
81\end{array}$ & $\begin{array}{l}5.68 \\
6.15 \\
9.79\end{array}$ \\
\hline Word & Pseudoword & $\begin{array}{r}794 \\
96 \\
77\end{array}$ & $\begin{array}{l}1.70 \\
3.66 \\
5.58\end{array}$ & $\begin{array}{r}832 \\
93 \\
82\end{array}$ & $\begin{array}{l}2.41 \\
3.86 \\
6.73\end{array}$ \\
\hline
\end{tabular}

* Mean. $†$ Standard deviation by subjects. $\ddagger$ Standard deviation by items.

\section{Results and Discussion}

Table 18 presents the mean latencies, standard deviations, and errors for the word and pseudoword targets in the conditions in which phonemic similarity was manipulated. As can be seen in Table 18, the phonemic similarity effect occurred for both sequence types. A 2 (PW-W sequence vs. W-PW sequence) $\times 2$ (phonemic similarity vs. phonemic dissimilarity) analysis of variance was conducted. The main effects of sequence $(\mathrm{PW}-\mathrm{W}=$ $765 \mathrm{msec}$ vs. W-PW $=814 \mathrm{msec}$ ) and phonemic similarity (phonemic similarity $=774 \mathrm{msec}$ vs. phonemic dissimilarity $=805 \mathrm{msec}$ ) were significant $\left[\min F^{\prime}(1,103)=\right.$ $13.11, p<.001$, and $\min F^{\prime}(1,102)=9.08, p<.01$, respectively]. The important interaction of phonemic similarity $\times$ sequence was not significant $\left(\min F^{\prime}<1\right)$. The sequence difference should be attributed primarily to the fact that words are accepted faster than pseudowords are rejected. Analysis of errors found only the sequence variable to be significant, with more errors produced on word targets $(5.97 \%)$ than on pseudoword targets $(2.06 \%)$ $\left[\min F^{\prime}(1,105)=9.58, p<.01\right]$. The conclusion to be drawn is that the phonemic similarity effect in lexical decision is due to the automatic, prelexical activation of phonological information.

\section{GENERAL DISCUSSION}

The present series of experiments used a paradigm in which two Serbo-Croatian words presented sequentially were phonemically similar or dissimilar and graphemically similar or dissimilar. Graphemic similarity was manipulated through the use of the two Serbo-Croatian alphabets. The second word was evaluated lexically or named. Comparisons of latencies and errors were made across stimulus pairs of which the following are typical: PUTIĆ-PUŽIĆ, similar phonemically and similar graphemically; ПУТИЋ-PUŽIĆ , similar phonemically, dissimilar graphemically; RAKUN-PUZZIĆ, a control in which the context is in the same alphabet as the target; PAKYH-PUŽIĆ, a control in which the context is in a different alphabet from the target. Experiments 1, 2, 3, 
4 , and 9 showed that the visual phonemic similarity effect in lexical decision does not depend on graphemic similarity. Experiments 5, 6, and 7 showed that the visual phonemic similarity effect in naming does not depend on graphemic similarity. For both lexical decision and naming, the phonemic similarity effect arises from the use in target processing of phonological information activated in context processing. Experiment 10 showed that this activation occurs under conditions that minimize the identification of the context. The activation of the phonological information underwriting the similarity effect appears to be automatic.

We have presented a view of the processing of SerboCroatian letter strings as involving, in bottom-up succession, connected layers of featural processing units, letter-, phoneme-, and word-processing units (Lukatela, Turvey, et al., 1989). To incorporate naming, a further layer of articulatory units is required. Of special significance are the letter-units-to-phoneme-units connections. These embody the grapheme-phoneme correspondences of the language. In the Serbo-Croatian orthography, unlike the English orthography, these correspondences are straightforward. All letters are pronounced, and their individual pronunciations are not altered significantly by the letter contexts in which they are embedded.

The network of letter-to-phoneme connections for a single letter position exhibits characteristics that are dictated by the bi-alphabetic nature of the language. Each letter unit connects to its corresponding phoneme unit. No phoneme units are duplicated. For the phoneme units connected to the unambiguous letter units shared by the two alphabets, there is one letter unit per phoneme unit. For all other phoneme units, there are two letter-unit connections per phoneme unit. That is, each unique Cyrillic, each unique Roman, and each ambiguous letter unit connects to a phoneme unit that is connected to one other letter unit. This pattern of connections is repeated across letter positions.

With the activation of phoneme units by letter units, a two-way interactive process is initiated between phoneme units and word units. Word units reflect the phonemic precision of the orthography. Each word unit represents a particular ordering of phoneme units together with their stress pattern. The access of word knowledge is seen to take place principally through the phonemelevel-to-word-level connections.

The foregoing concept of grapheme-phoneme rules is contrary to the view advanced in the literature on Englishword recognition and word pronunciation (e.g., Coltheart, 1978; Venezky, 1970). It rejects the idea that a rule expresses a regularity in which a single letter corresponds to a single phoneme. It promotes the idea that "rule" refers to any letter-to-phoneme correspondence in the language (see Rosson, 1985; Rumelhart \& McClelland, 1982). In brief, "rule" is replaced by "connection" (see also Van Orden, 1987). In English, the number of letter/phoneme rules interpreted in the preceding sense would be very large; there would be many connections representing the many relations at the grain size of individual letters and at coarser grains involving multiple letters. In Serbo-Croatian, by contrast, the number of rules-cum-connections is small. Besides number, English rules and Serbo-Croatian rules contrast in mean strength, specifically, the mean level of activation of a letter unit required to activate a phoneme unit. In Serbo-Croatian, the rules are stronger, on average, and the uniformity of strengths across the letter-to-phoneme connections is greater. The significance of these contrasts is highlighted in the comparative dependence of pronunciation in the two languages on word-level information. Paraphrasing and generalizing Rosson (1985), because the rules of SerboCroatian are few and strong (on the average), word-level information will be less critical; because the rules of English are many and weak (on the average) word-level information will predominate (but see Van Orden, 1987, for an alternative view).

Let us summarize how the present data bear on the preceding account of word processing in Serbo-Croatian. A phonemically similar context activates almost all of the phoneme units of the following target. The shared and unshared phoneme units, in turn, will activate all of the word units that contain these phonemes in the same positions. On presentation of the target, this patterning of phoneme and word units, and the interaction among them, comprises the background against which the target's processing takes place.

The task of lexical decision is constrained primarily by the individual states and collective dynamics of the word units. When a context and target are phonemically similar, and the target is a highly familiar item, the processing of the context results in inhibition of the target's representation. This is because, in consensus with Grossberg's (1978) principle of self-modulation, the proportion of the net inhibition felt by a given unit (in a set of activated units) is scaled positively to the given unit's level of activity, which is scaled positively to the given unit's activation threshold, which is scaled positively to the familiarity of the word that the given unit represents. As a consequence, high-familiarity targets are subject to high levels of inhibition during the processing of the context, with the result that phonemic similarity effects with highfamiliarity targets are negative, as evident in Experiments 3 and 4.

For low-familiarity target words and for pseudowords, a phonemically similar context will activate most of the phoneme units to be used in processing the target. In neither case, however, will there be an exceptionally high level of activation in any individual word unit. Consequently, no individual word unit will be subject to high levels of inhibition. For a low-familiarity word target, the low level of inhibition at the word-unit level means that the target's processing can benefit from the preactivation of the target's phoneme units and its word unit. Similarly, processing of a pseudoword target can benefit from the preactivation of the target's phoneme unit. Nevertheless, if the lexical decision process is understandable ultimately 
as a signal-detection problem, then decision speed and accuracy will vary inversely with the signal (activity level of target word unit)-to-noise (activity levels of other word units) ratio. Generally, this ratio would be smaller for pseudoword targets than for word targets. For pseudoword targets, therefore, the processing advantages of priming units below the word-unit level could be outweighed, more or less, by postlexical processing disadvantages. Differences in the lexical decision task between the phonemic similarity effects of low- and high-familiar words were shown by the similarity $\times$ target-familiarity interactions of Experiments 3 and 4. Differences in the lexical decision task between the phonemic similarity effects of pseudowords and words were shown in the similarity $\times$ lexicality interactions of Experiments 2, 4, and 9.

The task of naming letter strings is constrained primarily by the individual states and collective dynamics of the phoneme units. A context that primes the phoneme units of a subsequent letter string should facilitate naming. Moreover, according to the model, it should do so equally for words and pseudowords. In isolation, naming a word is distinguished from naming a pseudoword by the contribution of information from accessed word units. When a word is presented, one word unit achieves dominance at the word-unit level, reinforcing the states of the phoneme units. When a pseudoword is presented, no word unit, on the average, achieves dominance, and the reinforcement of phoneme units is, therefore, much less pronounced. The lexicality variable, by definition, is manifest primarily at the word-unit level-it is a matter of whether or not a word unit is fully activated in the processing of a letter string. The phonemic similarity variable operates, primarily, at the level of phoneme units-it is a matter of whether or not the target's phoneme units are activated. Consequently, in naming, the effects of the one variable should add to the effects of the other variable. Facilitation by phonemic similarity, and an additive relation of phonemic similarity and lexicality, were found in Experiments 5,6 , and 7 .

The significance of target familiarity in the phonemic similarity effect with lexical decision is understood in terms of the degree of inhibition generated at the wordunit level. Inhibition, however, does not occur between adjacent levels, only activation, meaning that phonemes relevant to the processing of the target will not be inhibited even if the word unit relevant to the processing of the target is inhibited. For both high- and low-familiar words, a phonemically similar context word will activate phoneme units relevant to naming the target. Downward activation from the word-unit level may boost these phoneme units, more or less. Although phonemic similarity and target familiarity affected naming, Experiment 7 showed that they did not interact.

The articulatory units in the model are assumed to connect to output phoneme units and to word units. The former connection specifies the phonemic content of the pronunciation; the latter connection specifies the prosody of the pronunciation. A phonemically similar context whose accent differs from that of the target will specify appropriate aspects of the target's phonemic content but inappropriate accent. A phonemically similar context of the preceding type should affect naming; it should not, however, affect lexical decision. Experiments 8 and 9 confirmed these features of the model. Only naming was affected by accent incongruity. Accent incongruity appears to slow the assembling of a pronunciation more than the specification of phonemic content speeds up the assembling of a pronunciation.

In sum, the pattern of results obtained in the present series of experiments can be given a consistent interpretation on the assumption that phonological information in the processing of Serbo-Croatian words is computed automatically prior to lexical access. Both lexical access and the assembling of pronunciations depend on this prelexical phonology

\section{REFERENCES}

Aaronson, D., \& Ferres, S. (1983). A model for coding lexical categories during reading. Journal of Experimental Psychology: $\mathrm{Hu}$ man Perception \& Performance, 9, 700-725

Balota, D. A. Chumbley, J. I. (1985). The locus of word-frequency effects in the pronunciation task: Lexical access and/or production? Journal of Memory \& Language, 24, 89-106

Baron, J. (1973). Phonemic stage not necessary for reading. Quarterly Journal of Experimental Psychology, 25, 241-246.

BECKER, C. A. (1976). Allocation of attention during visual word recognition. Joumal of Experimental Psychology: Human Perception \& Performance, 2, 556-566.

BECKER, C. A. (1979). Semantic context and word frequency effects in visual word recognition. Journal of Experimental Psychology: Human Perception \& Performance, 5, 252-259.

Carello. C.. Lukatela, G., \& Turvey, M. T. (1988). Rapid naming is affected by association but not by syntax. Memory \& Cognition, 16, 187-195.

Colombo, L. (1986). Activation and inhibition with orthographically similar words. Journal of Experimental Psychology: Human Perception \& Performance, 12, 226-234.

Coltheart, M. (1978). Lexical access in simple reading tasks. In G. Underwood (Ed.), Strategies of information processing (pp. 151. 216). London: Academic Press.

Coltheart, M., Besner, D., Jonasson, J. T. Davelaar, E. (1979). Phonological coding in the lexical decision task. Quarterly Journal of Experimental Psychology, 31, 489-505.

Coltheart, M., Davelaar, E., Jonasson, J. T., Besner, D (1977). Access to the internal lexicon. In S. Domic (Ed.), Attention and performance $V I$ (pp. 535-555). New York: Academic Press.

Davelaar, E., Coltheart, M., Besner, D., \& Jonasson, J. T, (1978). Phonological recoding and lexical access. Memory \& Cognition, 6, 391-402

EvetT, L. J., \& Humphreys, G. W. (1981). The use of abstract graphemic information in lexical access. Quarterly Joumal of Experimental Psychology, 33, 325-350.

Feldman, L. B., Kostić, A., Lukatela, G., \& Turvey, M. T. (1983). An evaluation of the "Basic orthographic Syllabic Structure" in a phonologically shallow orthography. Psychological Research, 45, 55-72.

Feldman, L. B., \& Turvey, M. T. (1983). Word recognition in SerboCroatian is phonologically analytic. Journal of Experimental Psychology: Human Perception \& Performance, 9, 288-298.

Forster, K. I. (1979). Levels of processing and the structure of the language processor. In W. E. Cooper \& E. C. Walker (Eds.). Sentence processing (pp. 27-85). Hillsdale, NJ: Erlbaum. 
FORSTER, K. I. (1987). Form-priming with masked primes: The best match hypothesis. In M. Coltheart (Ed.), Attention and performance $X I I$ (pp. 128-145). Hillsdale, NJ: Erlbaum.

Forster, K. I., \& Chambers, S. M. (1973). Lexical access and naming time. Journal of Verbal Learning \& Verbal Behavior, 12, 627-635.

Forster, K. I., Davis, C., Schoknecht, C., \& Carter, R. (1987). Masked priming with graphemically related forms: Repetition or partial activation? Quarterly Journal of Experimental Psychology, 39A, 211-251.

Frederiksen, J. R., \& Kroll, J. F. (1976). Spelling and sound: Approaches to the internal lexicon. Journal of Experimental Psychology: Human Perception \& Performance, 2, 361-379.

Frost, R., Bentin, S., \& Katz, L. (1987). Strategies for visual word recognition and orthographic depth: A multilingual comparison. Journal of Experimental Psychology: Human Perception \& Performance, 13, 104-115.

Gernsbacher, M. A. (1984). Resolving 20 years of inconsistent interactions between lexical familiarity and orthography, concreteness, and polysemy. Journal of Experimental Psychology: General, $113,256-281$.

GLUSHKo, R. (1979). The organization and activation of orthographic knowledge in reading aloud. Journal of Experimental Psychology: $\mathrm{Hu}$ man Perception \& Performance, 5, 674-691.

Green, D. W., \& Shallice, T. (1976). Direct visual access in reading for meaning. Memory \& Cognition, 4, 753-758.

GrossBerg, S. A. (1978). A theory of visual coding, memory, and development. In E. L. J. Leeuwenberg \& H. F. J. M. Buffart (Eds.), Formal theories of visual perception. New York: Wiley.

Hanson, V. L., \& Fowler, C. A. (1987). Phonological coding in word reading: Evidence from hearing and deaf readers. Memory \& Cognition, 15, 199-207.

Hawkins, H. L., Reicher, G., Rogers, M., \& Peterson, L. (1976). Flexible coding in word recognition. Journal of Experimental Psychology: Human Perception \& Performance, 2, 235-242.

HENDERSON, L. (1982). Orthography and word recognition in reading. New York: Academic Press.

Hillinger, M. L. (1980). Priming effects with phonemically similar words: The encoding-bias hypothesis reconsidered. Memory \& Cognition, 8, 115-123.

Humphreys, G. W., \& EveTt, L. J. (1985). Are there independent lexical and nonlexical routes in word processing? An evaluation of the dual-route theory of reading. Behavioral \& Brain Sciences, 8, 689-739.

Humphreys, G. W., EvetT, L. J., \& TAYlor, D. E. (1982). Automatic phonological priming in visual word recognition. Memory \& Cognition, 10, 576-590.

JORDAN, M. I. (1986). Serial order in behavior: A parallel distributed processing approach (Tech. Rep. No. 8604). San Diego: University of California, Institute for Cognitive Studies.

KaY, J., \& Marcell, A. J. (1981). One process, not two, in reading aloud: Lexical analogies do the work of non-lexical rules. Quarterly Journal of Experimental Psychology, 33A, 397-415.

Kolers, P. A. (1970). Three stages of reading. In H. Levin \& J. P. Williams (Eds.), Basic studies in reading (pp. 90-118). New York: Basic Books.

KuČERA, H., \& FrancIs, W. (1967). Computational analysis of presentday American English. Providence, RI: Brown University Press.

lukatela, G., Carello, C., Savić, M., \& Turvey, M. T. (1986). Hemispheric asymmetries in phonological processing. Neuropsychologica, 24, 341-350.

Lukatela, G., Carello, C., \& Turvey, M. T. (1987). Lexical representation of regular and irregular inflected nouns. Language \& Cognitive Processes, 2, 1-17.

lukatela, G., Feldman, L. B., Turvey, M. T., Carello, C., \& KATZ, L. (1989). Context effects in bi-alphabetical word perception. Journal of Memory \& Language, 28, 214-236.

Lukatela, G., Popadić, D., Ognjenović, P., \& Turvey, M. T. (1980). Lexical decision in a phonologically shallow orthography. Memory \& Cognition, 8, 124-132.

Lukatela, G., Savić, M., Gligorijević, B., Ognjenović, P., \& Turvey, M. T. (1978). Bi-alphabetical lexical decision. Language \& Speech, 21, 142-165.

Lukatela, G., \& TuRvey, M. T. (1980). Some experiments on the
Roman and Cyrillic alphabets of Serbo-Croatian. In J. F. Kavanagh \& R. L. Venezsky (Eds.), Orthography, reading, and dyslexio (pp. 227-247). Baltimore, MD: University Park Press.

Lukatela, G., Turvey, M. T., Feldman, L. B., Carello, C., \& KATZ, L. (1989). Alphabetic priming in bi-alphabetical word perception. Journal of Memory \& Language, 28, 237-254.

Martin, R. C., \& Jensen, C. R. (1988). Phonological priming in the lexical decision task: A failure to replicate. Memory \& Cognition, 16, 505-521.

MCClelland, J. L., \& RUMElhart, D. E. (1981). An interactive activation model of context effects in letter perception: Part I. An account of basic findings. Psychological Review, 88, 357-407.

McCusker, L. X., Hillinger, M. L., \& Bias, R. G. (1981). Phonological recoding and reading. Psychological Bulletin, 89, 217-245.

Merikle, P. M., \& Glick, M. I. (1976). Processing order in visual perception. Quarterly Journal of Experimental Psychology, 28, 17-26.

MEYer, D. E., SchVANeVeldt, R. W., \& RudDy, M. G. (1974). Functions of graphemic and phonemic codes in visual word-recognition. Memory \& Cognition, 2, 309-321.

NorRIs, D. (1986). Word recognition: Context effects without priming. Cognition, 22, 93-136.

PaAP, K. R., Newsome, S. L., McDonald, J. E., \& Schvaneveldt, R. W. (1982). An activation-verification model for letter and word recognition: The word superiority effect. Psychological Review, 89, 573-594.

Perfetti, C. A., Bell, L. C., \& Delaney, S. M. (1988). Automatic (prelexical) phonemic activation in silent word reading: Evidence from backward masking. Journal of Memory \& Language, 27, 59-70.

Rosson, M. B. (1985). The interaction of pronunciation rules and lexical representations in reading aloud. Memory \& Cognition, 13, 90-98.

Rubenstein, H., Lewis, S. S., \& Rubenstein, M. A. (1971). Evidence for phonemic recoding in visual word recognition. Journal of Verbal Learning \& Verbal Behavior, 10, 645-657.

Rumelhart, D. E., \& MCClelland, J. L. (1982). An interactive activation model of context effects in letter perception: Part 1 . The contextual enhancement effect and some tests and extensions of the model. Psychological Review, 89, 60-94.

SEIDENBERG, M. S. (1985). The time course of phonological code activation in two writing systems. Cognition, 19, 1-30.

Seidenberg, M. S., Waters, G. S., Sanders, M., \& Langer, P. (1984). Pre- and postlexical loci of contextual effects on word recognition. Memory \& Cognition, 12, 315-328.

Shulman, H. G., Hornak, R., \& Sanders, E. (1978). The effect of graphemic, phonetic, and semantic relationships on access to lexical structures. Memory \& Cognition, 6, 115-123.

SмIтH, F. (1971). Understanding reading. New York: Holt, Rinehart, \& Winston.

Stanovich, K. E., \& West, R. F. (1983). On priming by a sentence context. Journal of Experimental Psychology: General, 112, 1-36.

Turvey, M. T., Feldman, L. B., \& Lukatela, G. (1984). The SerboCroatian orthography constrains the reader to a phonologically analytic strategy. In L. Henderson (Ed.), Orthographies and reading (pp. 81-90). Hillsdale, NJ: Erlbaum.

VAN ORDEN, G. C. (1987). A ROWS is a ROSE: Spelling, sound, and reading. Memory \& Cognition, 15, 181-198.

VAN Orden, G. C., Johnston, J. C., \& Hale, B. L. (1988). Word identification in reading proceeds from spelling to sound to meaning. Journal of Experimental Psychology: Learning, Memory, \& Cognition, 14, 371-386.

VENEZKY, R. L. (1970). The structure of English orthography. The Hague: Mouton.

West, R. F., \& Stanovich, K. E. (1982). Source of inhibition in experiments on the effect of sentence context on word recognition. Journal of Experimental Psychology: Learning, Memory, \& Cognition, 5, 385-399.

West, R. F., \& Stanovich, K. E. (1986). Robust effects of syntactic structure on visual word processing. Memory \& Cognition, 14, 104-112.

(Manuscript received October 1, 1987; revision accepted for publication May 30, 1989.) 